\title{
Análise do efeito diurno do fator de visão do céu no microclima e nos níveis de conforto térmico em ruas de pedestres em Curitiba
}

\author{
Analysis of the daytime effect of the sky view factor on \\ the microclimate and on thermal comfort levels in \\ pedestrian streets of Curitiba
}

\section{Flavia Cristina Osaku Minella \\ Francine Aidie Rossi \\ Eduardo Leite Krüger}

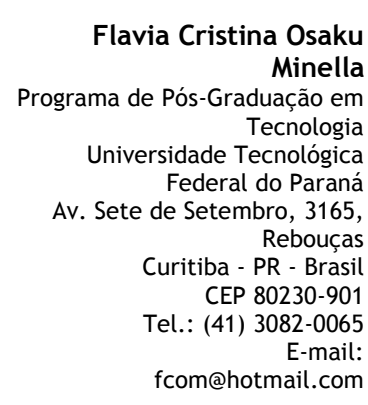

Francine Aidie Rossi Programa de Pós-Graduação em Universidade Tecnológica Federal do Paraná

Tel.: (41) 3077-4286

francinea.rossi@hotmail.com

Eduardo Leite Krüger Programa de Pós-Graduação em Tecnologia

Universidade Tecnológica

Federal do Paraná

Tel.: (41) 3310-4725 Ramal:

4725

E-mail: ekruger@utfpr.edu.br

Recebido em 29/06/2010

Aceito em 02/11/2010

\section{Resumo}

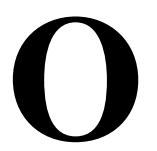

clima urbano é resultado das ações de diversas variáveis, entre elas o fator de visão do céu (FVC). O objetivo deste artigo é analisar o efeito diurno do FVC no microclima e nos níveis de conforto térmico em ruas de pedestre em Curitiba. Foram realizadas 13 medições, em 15 pontos com diferentes características urbanas, ao longo de quatro ruas de pedestres. Os resultados mostram baixa correlação entre o microclima e o FVC. Porém, foi possível verificar a relação existente entre a configuração urbana, a temperatura radiante média e a radiação solar. Além disso, é possível perceber a relação entre o FVC e os índices de conforto térmico PMV e PET. Para a situação de verão e em pontos com menor obstrução do céu, obteve-se maior desconforto para calor. No entanto, esses mesmos pontos podem apresentar melhor situação de conforto em dias com temperaturas mais baixas.

Palavras-chave: Fator de visão do céu. Conforto térmico em espaços abertos. Índices de conforto térmico.

\section{Abstract}

Urban climate is a result of several variables, including the sky view factor (SVF). The aim of this study is to investigate the diurnal influence of the sky view factor on the microclimate and on comfort levels, in pedestrian streets of Curitiba.

Thirteen measurements were made at 15 locations with different urban settings on 4 pedestrian streets. The results show a weak correlation between SVF and microclimate. However, it was possible to verify the relationship between SVF, mean radiant temperature and solar radiation. In addition, the results show the relationship between SVF and the comfort indices PMV and PET. In summer conditions and with lower obstruction of the sky, there was more discomfort caused by heat. However, the same points may present a better comfort situation on days with lower temperatures.

Keywords: Sky view factor. Thermal comfort in open spaces. Thermal comfort indices. 


\section{Introdução}

O processo de urbanização influi nas mudanças microclimáticas, acarretando em alterações nos balanços energético, hídrico e térmico e nos fluxos aerodinâmicos. As alterações no balanço de radiação referem-se ao decréscimo de radiação recebida em zonas sombreadas, ao aumento da radiação solar recebida e refletida internamente em cânions urbanos, à captação e armazenamento de calor pelos materiais de construção e à redução da radiação de onda longa emitida pela área urbana para a atmosfera devido às obstruções locais (OKE, 1978).

Estudos iniciais em clima urbano como o de Oke (1981) e o de Johnson e Watson (1984) basearamse nos modelos geométricos de cânions urbanos, considerando-se a razão entre a altura das edificações e a largura da via (H/W). De acordo com Chapman e Thornes (2004), os métodos desenvolvidos na década de 80, em geral, assumiam cânions com dimensões "ideais" (cânions simétricos de profundidade infinita), gerando resultados estimados. A simplificação dos cânions urbanos, em geral, não condiz com a forma urbana de algumas cidades, as quais apresentam edificações com perfis verticais diversificados. Nesse sentido, o fator de visão do céu (FVC), representado pelo símbolo $\Psi$ s, pode ser considerado um parâmetro mais próximo da realidade.

O FVC está relacionado à quantidade de céu visível de determinado ponto, ou seja, o céu disponível para a dispersão de energia térmica. Johnson e Watson (1984) consideram o FVC como a razão entre a radiação solar recebida (ou emitida) por uma superfície plana comparada com aquela recebida (ou emitida) por todo o entorno. $\mathrm{O}$ valor do FVC varia de 0 (zero) a 1 , sendo o valor 1 correspondente a uma área sem qualquer obstáculo que se interponha entre o ponto escolhido e o céu. Para Souza, Rodrigues e Mendes (2003, p. 671), representa uma obstrução à abóbada celeste "[. . . ] qualquer edificação, elemento ou equipamento urbano, pertencente ao plano do observador posicionado na camada intra-urbana [ . . . ]".

O balanço de radiação em um cânion urbano depende do FVC. Embora parâmetros como o calor liberado pelas ações antropogênicas e as propriedades térmicas dos materiais estejam relacionados com a intensidade da ilha de calor noturna, simulações realizadas por Oke et al. ${ }^{1}$ (1991, apud CHAPMAN; THORNES ;

1 OKE, T. R. et al. Simulation of Surface Urban Heat Islands under 'Ideal' Conditions at Night: part 2: diagnosis of causation. Boundary-Layer Meteorology, v. 56, p. 339358, 1991.
BRADLEY, 2001) apontam que o FVC pode, isoladamente, produzir uma diferença entre a temperatura urbana e a rural de $5^{\circ} \mathrm{C} \mathrm{a} 7^{\circ} \mathrm{C}$.

O FVC tem sido comumente utilizado em estudos de trocas de energia (CHAPMAN; THORNES, 2004). Ribeiro, Fidelis e Carvalho (2008) relatam que o fator de visão do céu exerce influência, também, no ganho de radiação solar direta, influenciando a ilha de calor diurna ${ }^{2}$ ou estresse térmico diurno. No entanto, observa-se que há uma predominância de estudos que relacionam FVC e ilha de calor noturna, em relação àqueles voltados ao período diurno.

Para um estudo que buscava relacionar as ilhas de calor com o tamanho das cidades, Yamashita et al. (1986) selecionaram cidades de pequeno a médio porte próximas a Tóquio $\left(35^{\circ} 40^{\prime} \mathrm{N}\right)$, Japão. As medições foram realizadas em todas as épocas do ano, tanto no período diurno como no período noturno. Nas cinco cidades monitoradas verificouse a existência de diferenças de temperatura do ar entre as áreas mais adensadas e o entorno, sendo o FVC considerado um indicador para expressar os efeitos da urbanização sobre a intensidade da ilha de calor.

Unger (2004) fornece uma revisão detalhada sobre a relação entre temperatura do ar e FVC e apresenta o resultado de um estudo realizado em Szeged $\left(46^{\circ} 15^{\prime} \mathrm{N}\right)$, Hungria. Os monitoramentos, realizados pela técnica de transectos móveis, ocorreram em um período de 1 ano, totalizando 35 medições noturnas, que englobaram quase toda a área urbana da cidade. De acordo com as conclusões obtidas pelo autor, a geometria urbana, definida pelo FVC, é um fator determinante para a distribuição da temperatura do ar (T) na cidade, mesmo em condições de tempo menos favoráveis. $\mathrm{O}$ coeficiente de determinação $\left(\mathrm{R}^{2}\right)$ encontrado foi de 0,47 .

Eliasson (1996) analisou a distribuição da temperatura horizontal em relação a diferentes geometrias urbanas e uso do solo na cidade de Göteborg (57 42' N), Suécia. As medições foram realizadas em um período de 3 anos (1988, 1989, 1990) e as análises restringiram-se às informações noturnas. De acordo com os resultados, a maior variação de temperatura do ar entre o cânion e a

\footnotetext{
${ }^{2}$ Embora Oke (1978) defina ilha de calor como um fenômeno tipicamente noturno, o termo "ilha de calor diurna” também tem sido adotado. Cabe ressaltar que os processos que as geram são diferenciados, pois, enquanto a ilha de calor diurna sofre influência da incidência direta de radiação solar, a ilha de calor noturna decorre da menor perda de radiação de onda longa das superfícies urbanas para a atmosfera.
} 
área aberta foi inferior a $3{ }^{\circ} \mathrm{C}$, o que demonstra pouca influência do FVC para a determinação da temperatura do ar. Corroborando essa afirmação, Upmanis e Chen (1999), em um estudo na mesma localidade, afirmam que o FVC apresenta correlação significativa com a temperatura de superfície, mas não com a temperatura do ar.

Com um estudo realizado em Göteborg, Svensson (2004) comprova que há forte correlação entre ilha de calor noturna e FVC. Utilizaram-se para o estudo dados de 16 pontos fixos, bem como dados de medições móveis coletados durante 36 dias entre 1988 e 1991, em épocas com temperaturas mais baixas. A autora analisou a diferença de FVCs obtidos por meio de fotografias olho de peixe em diferentes níveis ( $2 \mathrm{~m}$ acima do solo e ao nível do solo) e, por meio de análise de regressão, determinou como essa diferença influi na relação entre as variáveis. $\mathrm{O}$ coeficiente de determinação entre FVC ao nível do solo e a temperatura do ar foi de 0,62 , enquanto a $2 \mathrm{~m}$ de altura foi de 0,60 . Svensson (2004) sugere que as diferenças encontradas na literatura estão relacionadas com o procedimento de obtenção desses dados.

No Brasil, em um estudo na cidade de Bauru $\left(22^{\circ}\right.$ 19' S), Souza (2007), por intermédio de um algoritmo computacional, determinou o FVC para 40 pontos de medição. Foram coletados dados de temperatura do ar e, posteriormente, correlacionaram-se as informações obtidas com os valores de FVC. A análise mostrou que não houve uma tendência clara entre FVC e as médias de temperatura do ar. Conforme a autora, os valores máximos de temperatura, tanto no verão como no inverno, foram encontrados em áreas com valores de FVC mais baixos, sendo essas as áreas mais desconfortáveis termicamente. Ainda em relação ao conforto térmico, os resultados indicaram que o FVC possui maior influência no período de verão do que no de inverno.

Apesar de o FVC ser uma simples parametrização, o cálculo para sua obtenção tem sido um desafio para os climatologistas (CHAPMAN; THORNES, 2004). Diferentes métodos são apresentados para o cálculo de obtenção do FVC. Basicamente, o FVC pode ser obtido por métodos analíticos (OKE, 1981; JOHNSON; WATSON, 1984), métodos fotográficos - uso de programas específicos (CHAPMAN; THORNES; BRADLEY, 2001; MOIN; TSUTSUMI, 2004; CORREA et al., 2005), conjunto de dados de base em três dimensões acoplados a um Sistema de Informações Geográfica (SIG) (SOUZA; RODRIGUES; MENDES, 2003), métodos que utilizam Sistema de Posicionamento Global (GPS) (CHAPMAN; THORNES, 2004) e, mais recentemente, imagens com um dispositivo que mostra as diferenças térmicas entre as obstruções e o céu (CHAPMAN et al., 2007).

Considerando a relevância do FVC como indicador do nível de urbanização local, o objetivo deste artigo é analisar o efeito diurno do FVC no microclima e nos níveis de conforto térmico na cidade de Curitiba, Brasil. Além disso, são comparadas as sensações térmicas dos transeuntes com as sensações térmicas para um homem padrão. Para tal, utilizaram-se os índices de conforto térmico Voto Médio Estimado (PMV) e Temperatura Fisiológica Equivalente (PET). O período diurno foi considerado por ser o período principal destinado às atividades comerciais e de grande movimentação de pedestres nas ruas estudadas. O estudo se enquadra no escopo de uma pesquisa mais abrangente, tratando de conforto térmico em espaços abertos em Curitiba.

\section{Índices de Conforto Térmico - PMV e PET}

A partir de meados do século XVII, foram registradas as primeiras medições de temperatura do ar. Nessa época, questões referentes à sensação térmica em ambientes começaram a ser levantadas. Mas é no início do século XIX que os primeiros estudos relacionados ao estresse térmico começaram a ser realizados (MONTEIRO; ALUCCI, 2007).

Fanger (1982) apresentou um método para avaliar a sensação térmica de pessoas expostas a um mesmo ambiente, o índice Voto Médio Estimado (PMV - Predicted Mean Vote). Esse índice é decorrente de uma equação geral de conforto que considera tanto as variáveis climáticas como as variáveis pessoais. O PMV prediz o valor médio dos votos de sensação térmica de um grupo de pessoas e tem como base o balanço térmico do corpo humano, ou seja, quando o calor interno produzido pelo corpo é igual à perda de calor para o ambiente. Os votos são dados em uma escala de 7 pontos, variando de muito frio $(-3)$ até muito calor (+3), sendo o valor de neutralidade térmica correspondente a zero. Dessa conceituação, obtiveram-se os valores individuais de desconforto, calculados pelo índice de Porcentagem de Pessoas Insatisfeitas (PPD Predicted Percentage of Dissatisfied), que estabelece uma predição quantitativa da porcentagem de pessoas em desconforto, tanto para o calor como para o frio. A norma ISO 7730 (ISO, 2005) estabelece que em um ambiente termicamente confortável o PPD não deve ultrapassar $10 \%$, valor que corresponde à faixa entre $-0,5$ e $+0,5$. 
Para Höppe (1999, p. 72), os modelos de trocas de calor de aplicação mais universais são aqueles que permitem a estimativa dos valores de "[...] temperatura da pele, temperatura interna, taxa de suor, ou de pele úmida reais do corpo humano [...]", considerando-se para isso os " $[\ldots]$ processos termorregulatórios básicos como a vasodilatação e a taxa de suor psicológica [...]". Essa é a fundamentação do modelo Munich Energy-balance Model for Individuals (MEMI), que foi desenvolvido por Höppe em 1984 e que originou o índice denominado Temperatura Fisiológica Equivalente (PET - Physiological Equivalent Temperature).

Segundo Höppe (1999), o PET, expresso em graus Celsius, é definido como a temperatura fisiológica equivalente, em determinado ambiente (interno ou externo), à temperatura do ar de um ambiente interno de referência, no qual o balanço térmico humano é mantido com a temperatura da pele e do centro do corpo iguais àquelas das condições em avaliação. Nesse sentido, o índice PET permite ao indivíduo a comparação dos " [...] efeitos integrais das complexas condições externas com a sua própria experiência no ambiente interno [...]" (LAMBERTS; ANDREASI, 2003, p. 51).

Para a obtenção do PET, os dados climáticos do ambiente de referência e os dados individuais são estabelecidos da seguinte forma:

(a) velocidade do ar de $0,1 \mathrm{~m} / \mathrm{s}$;

(b) temperatura radiante média igual à temperatura do ar; pressão de vapor de água de 12 $\mathrm{hPa}$ (umidade relativa de $50 \%$ a uma temperatura do ar de $20^{\circ} \mathrm{C}$ );

(c) metabolismo de $80 \mathrm{~W}$ (atividade leve); e (d) vestimenta de 0,9 clo.

Baseando-se no PET, o conforto térmico para um ambiente padrão seria próximo dos $21^{\circ} \mathrm{C}$ (HÖPPE, 1999), ou correspondente a uma faixa entre $18^{\circ} \mathrm{C} \mathrm{e}$ $23{ }^{\circ} \mathrm{C}$, conforme Mayer e Matzarakis (1998). "Valores mais altos indicam uma possibilidade crescente de stress térmico, ao passo que valores mais baixos indicam condições muito frias para conforto [...]" (LOIS; LABAKI, 2001, p. 5).

Os índices PMV e PET são amplamente empregados em estudos em espaços externos (BRUSANTI; FONTES, 2009; DACANAL et al., 2009; SHIMAKAW A; BUENOBARTHOLOMEI, 2009; ANANIAN; FONTES; SILVA, 2009). A Tabela 1 mostra os níveis de estresse térmico e a sensação térmica para esses índices.

\section{Descrição da área de estudo}

Curitiba encontra-se na região Sul do Brasil, latitude $25^{\circ} 31^{\prime} \mathrm{S}$, longitude $49^{\circ} 11^{\prime} \mathrm{W}$ e altitude de $917 \mathrm{~m}$ acima do nível do mar. Abrange uma área de $435 \mathrm{~km}^{2}$ e possui uma população de aproximadamente 1.800.000 habitantes (IBGE, 2007). A cidade situa-se abaixo do Trópico de Capricórnio, no primeiro planalto paranaense. De acordo com a classificação de Köppen-Geiger, o clima de Curitiba é predominantemente mesotérmico, com verões frescos $(\mathrm{Cfb})$ e com invernos tipicamente secos (IPPUC, 2009). As precipitações são da ordem de $1.600 \mathrm{~mm}$ anuais. Segundo o Zoneamento Bioclimático Brasileiro (ABNT, 2005), Curitiba está na Zona Bioclimática I, a mais fria das oito zonas, correspondente a $0,8 \%$ do território nacional.

Tabela 1 - Sensação térmica e nível de estresse térmico para os índices PMV e PET

\begin{tabular}{|c|c|c|}
\hline PMV PET & Sensação Humana & Nível de estresse térmico \\
\hline \multirow{2}{*}{$-3,5 \quad 4^{\circ} \mathrm{C}$} & muito frio & estresse extremo ao frio \\
\hline & frio & estresse forte ao frio \\
\hline$-2,5 \quad 8^{\circ} \mathrm{C}$ & pouco frio & estresse moderado ao frio \\
\hline$-1,513{ }^{\circ} \mathrm{C}$ & leve frio & estresse leve ao frio \\
\hline$-0,518{ }^{\circ} \mathrm{C}$ & confortável & sem estresse térmico \\
\hline $0,5 \quad 23{ }^{\circ} \mathrm{C}$ & leve calor & estresse leve ao calor \\
\hline $1,529^{\circ} \mathrm{C}$ & pouco calor & estresse moderado ao calor \\
\hline $2,535^{\circ} \mathrm{C}$ & calor & estresse forte ao calor \\
\hline $3,541^{\circ} \mathrm{C}$ & muito calor & estresse extremo para calor \\
\hline
\end{tabular}

Fonte: modificado de Mayer e Matzarakis (1998). 
Medições meteorológicas oficiais são coletadas pelo Instituto Nacional de Meteorologia (INMET) em uma estação no Centro Politécnico da Universidade Federal do Paraná, na região leste da cidade. A estação se encontra em terreno com superfície gramada, com poucas árvores esparsas e com três construções de pequeno porte, sendo chamada neste artigo de "estação de referência".

A área de estudo localiza-se no centro da cidade de Curitiba e compreende os trechos de pedestres das Ruas XV de Novembro e Saldanha Marinho (implantadas no sentido E-W), Travessa Oliveira Bello e Rua Senador Alencar Guimarães (orientação axial NW-SE), e Praça Generoso Marques.

O calçadão da Rua XV de Novembro faz parte da história do urbanismo brasileiro por ter se tornado, em 1972, a primeira rua de pedestres do país. Atualmente, a Rua das Flores, como é popularmente chamada, faz parte da identidade cultural da cidade, sendo caracterizada por um fluxo intenso e constante de transeuntes. Segundo a Associação Comercial do Paraná (2007), 140.000 pessoas circulam por dia pelo calçadão. Desde seu surgimento, a via é uma das principais artérias comerciais da cidade (Figura 1).

\section{Materiais e método}

O estudo é classificado como correlacional, apoiado em observações de campo, e está dividido em quatro etapas principais:

(e) determinação dos valores de FVC dos pontos a serem monitorados nas ruas de pedestres citadas, por meio da análise de fotos olho de peixe inseridas no programa RayMan (descrito a seguir);

(f) monitoramento das variáveis climáticas e obtenção de variáveis pessoais a partir de dados coletados com aplicação de questionários de conforto com a população local nos pontos selecionados;

(g) utilização do programa RayMan para a definição dos índices PMV e PET para a população local e para o homem padrão; e

(h) análises dos resultados com a verificação do efeito diurno do FVC no microclima e nos níveis de conforto térmico dos transeuntes.

\section{Determinação do Fator de Visão do Céu}

A primeira etapa desta pesquisa consistiu na determinação dos valores de fator de visão do céu (FVC) em todas as quadras que compõem o trecho de pedestres da Rua XV de Novembro e entorno. Para a obtenção das fotos foi utilizada a câmera Nikon CoolPix 4500 com lente olho de peixe FCE8. Procurou-se mapear pontos na extensão que abrange desde a Praça Santos Andrade até a Praça General Osório (pontos 1 a 11), englobando todas as quadras do calçadão da Rua XV de Novembro. Além destes, selecionaram-se pontos no entorno do calçadão: Rua Saldanha Marinho (pontos $12 \mathrm{e}$ 13), Praça Generoso Marques (pontos 14 a 16), Travessa Oliveira Bello (ponto 17) e Rua Senador Alencar Guimarães (ponto 18), conforme a Figura 2 .

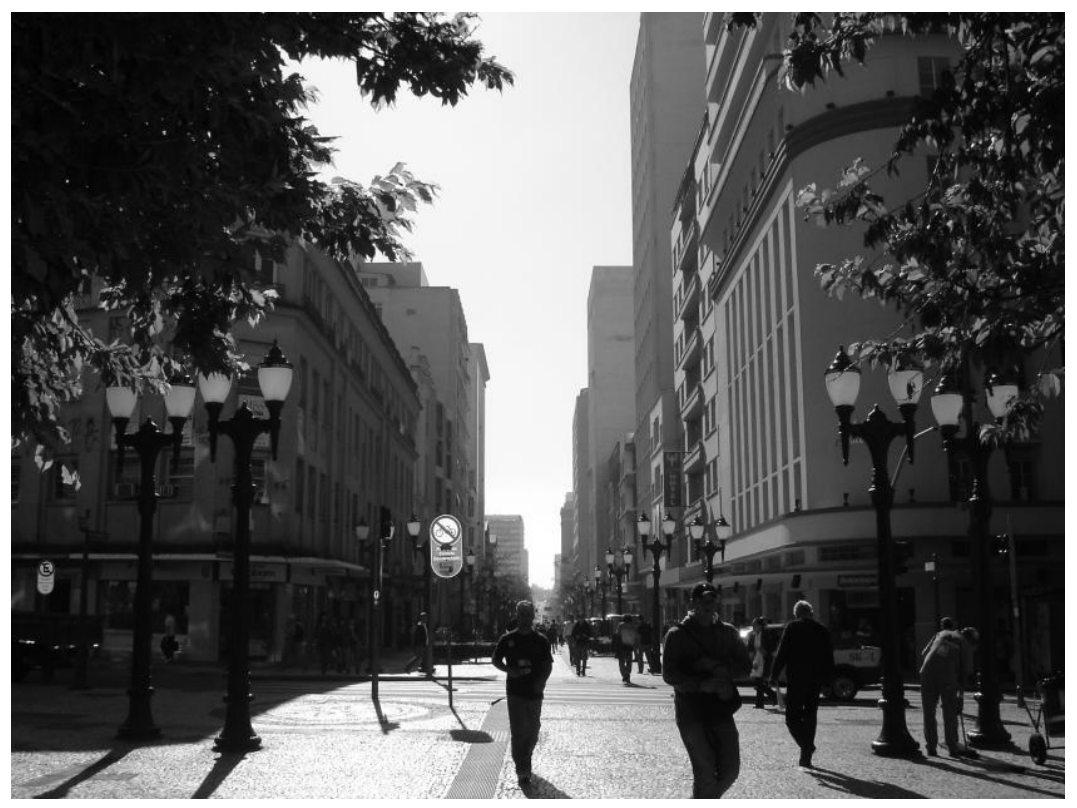

Figura 1 - Calçadão da Rua XV de Novembro 


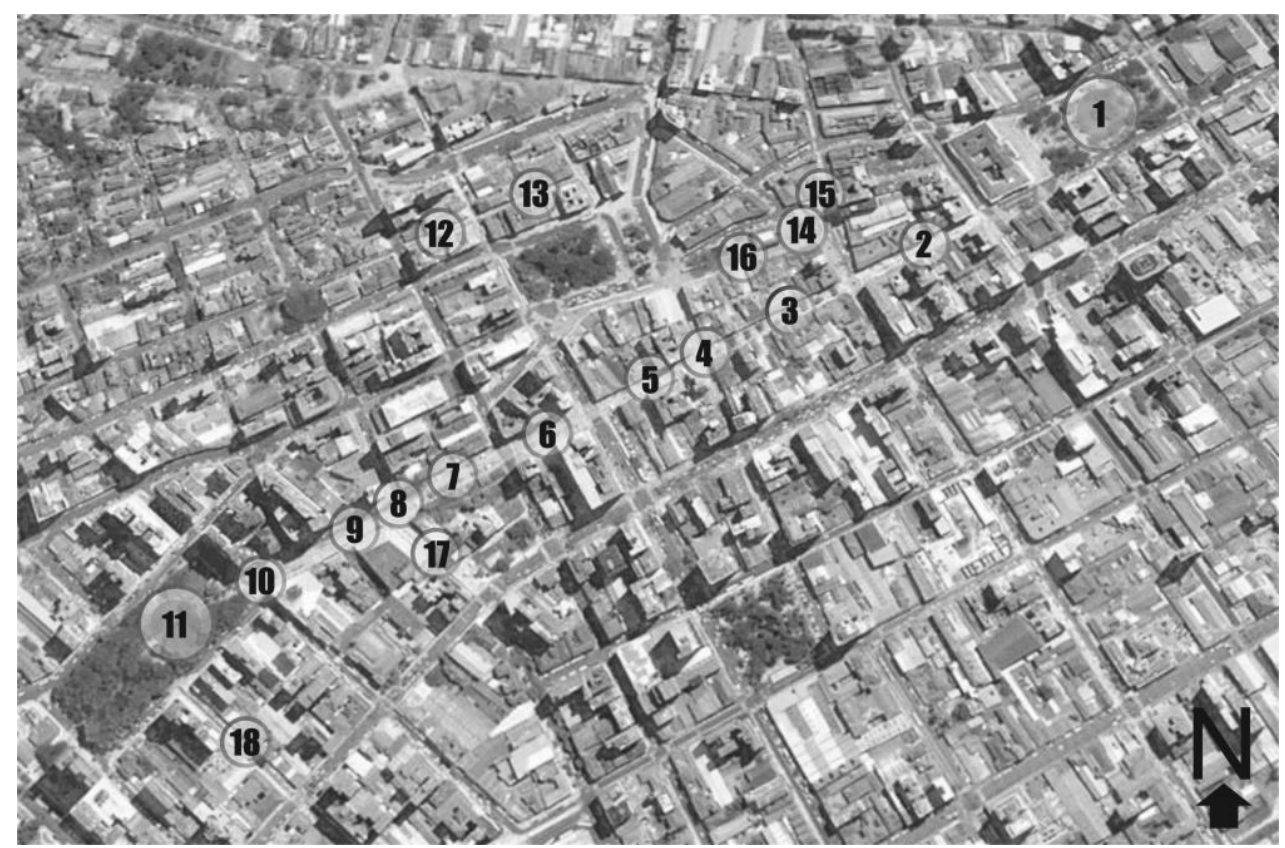

Figura 2 - Localização dos pontos selecionados para a obtenção do FVC

Ao todo, foram consideradas 18 localidades passíveis de monitoramento, totalizando 19 pontos, uma vez que o ponto 6 foi subdividido em dois pontos (6a e 6b). Desse total, selecionaram-se 15 pontos para medição, havendo repetição de alguns deles. O resultado das imagens olho de peixe de cada ponto monitorado com o respectivo valor de FVC está apresentado na Figura 3.

Os pontos de monitoramento foram sempre centralizados em relação à quadra, exceto nos seguintes locais: ponto 9, uma vez que esta quadra é a única com passagem para veículos; ponto 10 , situado no entorno da Praça General Osório; ponto 16, localizado no entorno da Praça Generoso Marques; e ponto 6, por haver uma fonte centralizada na quadra.

Em relação ao estabelecimento dos pares de medição, procurou-se comparar diferentes situações urbanas, como: cânions urbanos com diferenças consideráveis no valor de FVC, como os pares 2 e 7; pares com pouca diferença na quantidade de céu obstruído, como os pontos $8 \mathrm{e}$ 16; e comparação de cruzamento de vias com cânion e com praça seca, pares 4 e 9 e pares 4 e 14 respectivamente. Ressalta-se que, embora alguns pares apresentem valores de FVC semelhantes, suas configurações urbanas (regularidade na altura das edificaçõos, ponto em cruzamento de vias, etc.) são distintas.

\section{Caracterização do programa RayMan}

O programa RayMan permite a obtenção de índices de conforto como o PMV e PET. Por considerar as complexas estruturas urbanas, é de grande utilidade para a climatologia e o planejamento urbano. O programa foi desenvolvido por Andreas Matzarakis e é de domínio público (http://www.mif.unifreiburg.de/RayMan).

Para o cálculo dos fluxos de radiação e índices térmicos, o modelo considera os dados de entrada gerais (data, horário, longitude, latitude, altitude), as variáveis climáticas (temperatura do ar, umidade relativa do ar, velocidade do vento, nebulosidade, radiação solar global), além dos dados fisiológicos (peso, altura, idade, sexo, atividade e vestimenta). A temperatura radiante média (Trm) pode ser inserida, se conhecida, ou calculada pelo programa.

O modelo possibilita que determinada localidade seja graficamente representada com a inserção de dados de implantação e dimensões das edificações e vegetação. Por meio desse sistema de dados gráficos, é possível a visualização de áreas sombreadas pelos obstáculos naturais e artificiais, além do cálculo do FVC. Uma alternativa para a obtenção do FVC é por meio da inserção de fotos olho de peixe. As imagens podem ser importadas e editadas no próprio software. 


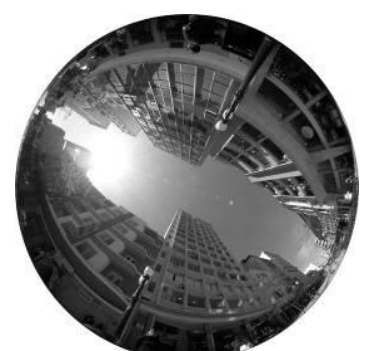

Ponto $2 \mid \mathrm{FVC}=0,20$

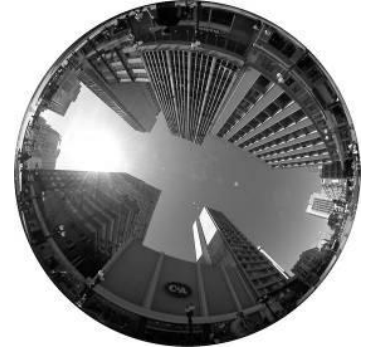

Ponto 6a $\mid \mathrm{FVC}=0,26$

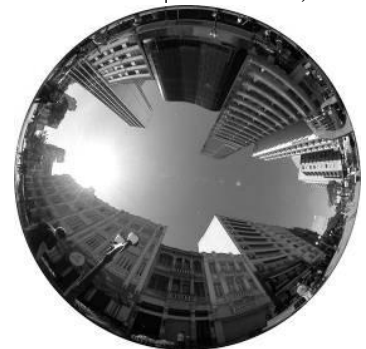

Ponto $9 \mid \mathrm{FVC}=0,29$

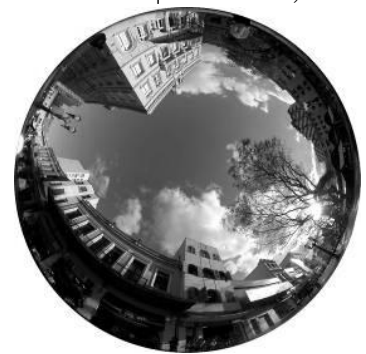

Ponto $16 \mid \mathrm{FVC}=0,38$

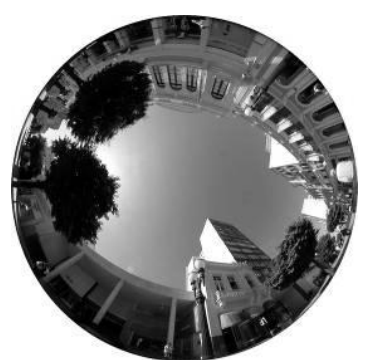

Ponto $3 \mid \mathrm{FVC}=0,32$

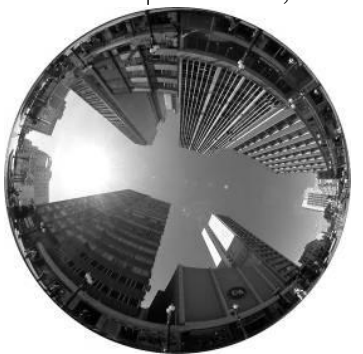

Ponto $6 \mathrm{~b} \mid \mathrm{FVC}=0,27$

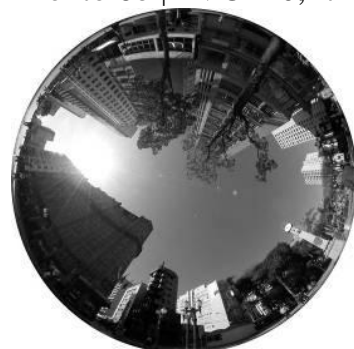

Ponto $10 \mid \mathrm{FVC}=0,30$

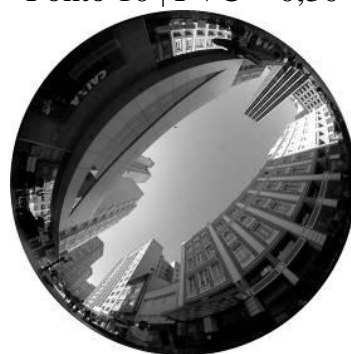

Ponto $17 \mid \mathrm{FVC}=0,21$

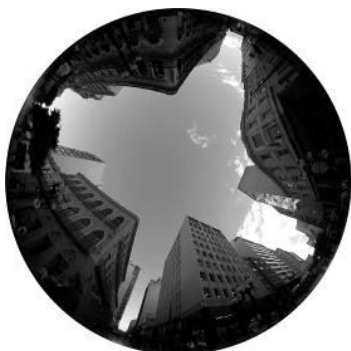

Ponto $4 \mid \mathrm{FVC}=0,34$

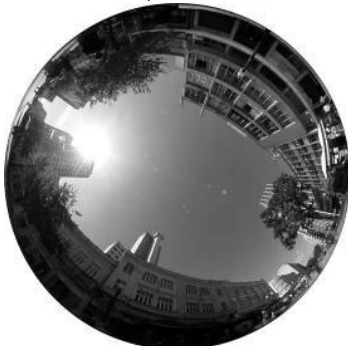

Ponto $7 \mid \mathrm{FVC}=0,39$

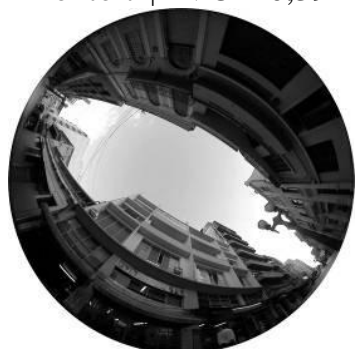

Ponto $13 \mid \mathrm{FVC}=0,21$

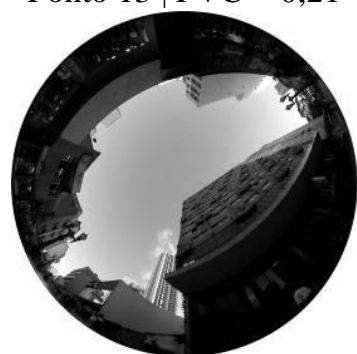

Ponto $18 \mid \mathrm{FVC}=0,30$

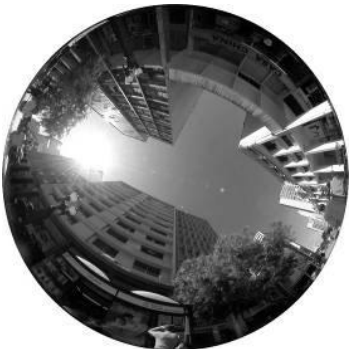

Ponto $5 \mid \mathrm{FVC}=0,22$

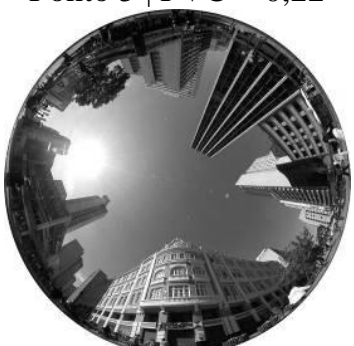

Ponto $8 \mid \mathrm{FVC}=0,37$

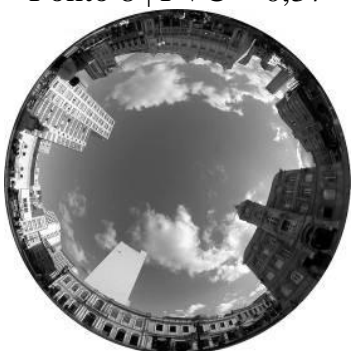

Ponto $14 \mid \mathrm{FVC}=0,55$

Figura 3 - Foto olho de peixe e FVC dos pontos monitorados

\section{Monitoramento das variáveis climáticas}

As coletas de dados climáticos foram possíveis com o uso de duas estações meteorológicas da marca HOBO, modelo H21-001 (Figura 4). Cada estação estava equipada com os seguintes instrumentos:

(a) sensor de temperatura e umidade (S-THBM002);

(b) piranômetro de silício (S-LIB-M003) e;

(c) sensor de direção e velocidade do vento (SWCA-M003).

As faixas de precisão desses instrumentos (Tabela 2) satisfazem as recomendações da norma ISO 7726 (ISO, 1998), que dispõe sobre os instrumentos para a medição de variáveis físicas.
Os sensores de temperatura do ar e umidade relativa foram fixados na altura de $110 \mathrm{~cm}$, conforme a ISO 7726 (ISO, 1998). O piranômetro foi fixado a $160 \mathrm{~cm}$, acima dos demais sensores, e orientado para o norte, para evitar sombras sobre ele. $\mathrm{O}$ anemômetro foi fixado a $210 \mathrm{~cm}$, conforme recomendado por Campbell (1997).

Para se obter a temperatura radiante média, foram utilizados termômetros de globo de cobre, fixados na altura de $110 \mathrm{~cm}$, com $\varnothing=2 \%$, pintados na cor RAL-7001 (cinza) (THORSSON et al., 2007). Os globos estavam equipados com os seguintes instrumentos:
(a) sensor de temperatura 12-Bit (S-TMB-M002) e;
(b) HOBO Pro V2 logger (U23-004). 


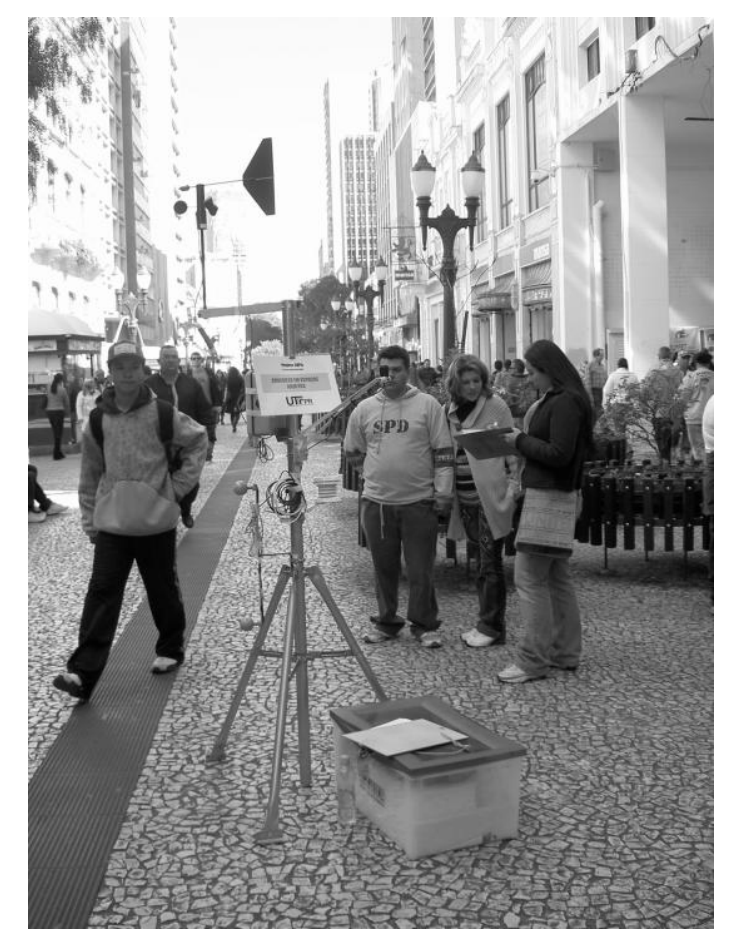

Figura 4 - Estação meteorológica НОBO

Tabela 2 - Faixa de precisão dos instrumentos segundo a norma ISO 7726:1998

\begin{tabular}{|c|c|c|c|c|}
\hline Variáveis & $\begin{array}{c}\text { Faixa } \\
\text { para } \\
\text { conforto }\end{array}$ & Precisão para conforto & $\begin{array}{c}\text { Faixa } \\
\text { para } \\
\text { estresse }\end{array}$ & Precisão para estresse \\
\hline $\begin{array}{l}\text { Temperatura do ar } \\
\qquad(\mathrm{T})\end{array}$ & $\begin{array}{c}10 \text { a } 40 \\
{ }^{\circ} \mathrm{C}\end{array}$ & $\begin{array}{l}\text { Desejada: } \pm 0,5^{\circ} \mathrm{C} \\
\text { Requerida: } \pm 0,2^{\circ} \mathrm{C}\end{array}$ & $\begin{array}{l}-40 \text { a } 120 \\
{ }^{\circ} \mathrm{C}\end{array}$ & $\begin{array}{c}\text { Desejada: } \\
\pm 0,5^{\circ} \mathrm{C}\left(0 \text { a } 50{ }^{\circ} \mathrm{C}\right) \\
\text { Requerida: } \\
\pm 0,25{ }^{\circ} \mathrm{C}\left(0 \text { a } 50{ }^{\circ} \mathrm{C}\right)\end{array}$ \\
\hline $\begin{array}{l}\text { Temperatura radiante } \\
\text { média } \\
\text { (Trm) }\end{array}$ & $\begin{array}{c}10 \text { a } 40 \\
{ }^{\circ} \mathrm{C}\end{array}$ & $\begin{array}{c}\text { Desejada: } \pm 2{ }^{\circ} \mathrm{C} \\
\text { Requerida: } \pm 0,2{ }^{\circ} \mathrm{C}\end{array}$ & $\begin{array}{c}-40 \mathrm{a} \\
150^{\circ} \mathrm{C}\end{array}$ & $\begin{array}{c}\text { Desejada: } \\
\pm 5{ }^{\circ} \mathrm{C}\left(0 \text { a } 50{ }^{\circ} \mathrm{C}\right) \\
\text { Requerida: } \\
\pm 5^{\circ} \mathrm{C}\left(0 \text { a } 50{ }^{\circ} \mathrm{C}\right)\end{array}$ \\
\hline $\begin{array}{l}\text { Velocidade do ar } \\
\text { (va) }\end{array}$ & $\begin{array}{c}0,05 \text { a } 1 \\
\mathrm{~m} / \mathrm{s}\end{array}$ & $\begin{array}{c}\text { Desejada: } \\
\pm(0,05+0,05 \mathrm{va}) \mathrm{m} / \mathrm{s} \\
\text { Requerida: } \\
\pm(0,02+0,07 \mathrm{va}) \mathrm{m} / \mathrm{s}\end{array}$ & $\begin{array}{c}0,2 \mathrm{a} \\
20 \mathrm{~m} / \mathrm{s}\end{array}$ & $\begin{array}{c}\text { Desejada: } \\
\pm(0,1+0,05 \mathrm{va}) \mathrm{m} / \mathrm{s} \\
\text { Requerida: } \\
\pm(0,05+0,05 \mathrm{va}) \mathrm{m} / \mathrm{s}\end{array}$ \\
\hline $\begin{array}{l}\text { Umidade absoluta } \\
\text { (pa) }\end{array}$ & $\begin{array}{c}0,5 \text { a } 3,0 \\
\mathrm{kPa}\end{array}$ & $\pm 0,15 \mathrm{kPa}|\mathrm{Tr}-\mathrm{T}|<10^{\circ} \mathrm{C}$ & $\begin{array}{c}0,5 \mathrm{a} \\
6,0 \mathrm{kPa}\end{array}$ & $\pm 0,15 \mathrm{kPa}|\mathrm{Tr}-\mathrm{T}|<20{ }^{\circ} \mathrm{C}$ \\
\hline
\end{tabular}

A temperatura radiante média foi calculada pela fórmula para convecção forçada, definida pela ISO 7726 (ISO, 1998). Os dados foram gravados de 5 em 5 segundos, e depois trabalhados para compor o minuto.

O monitoramento das variáveis microclimáticas ocorreu sempre em pares e simultaneamente em períodos de 4 horas (início às 11 h01min e término às $15 \mathrm{~h} 00 \mathrm{~min})$. No total, foram 13 dias de monitoramento ao longo dos meses de janeiro a agosto de 2009.

\section{Cálculos dos índices de conforto}

Os índices de conforto utilizados neste estudo foram o PMV e o PET, calculados por meio do programa RayMan. 
A norma ISO 8896 (ISO, 2004) estipula características para um homem considerado padrão. Neste artigo, são comparadas as sensações térmicas para esse homem padrão com os votos de sensação real, obtidos por meio dos questionários.

Para o cálculo da sensação térmica do homem padrão, as seguintes características foram consideradas: idade 30 anos, altura $1,75 \mathrm{~m}$ e peso $70 \mathrm{~kg}$. O valor de isolamento térmico das roupas considerado foi de 0,5 clo para dias com temperaturas altas (medição de janeiro até maio) e de 1,0 clo para dias com temperaturas baixas (medição de junho até agosto). A taxa metabólica utilizada foi de $110 \mathrm{~W} / \mathrm{m}^{2}$, correspondente a caminhada em superfície plana a $2 \mathrm{~km} / \mathrm{h}$ (ISO, 2005).

Para o cálculo da sensação real, as variáveis pessoais e de sensação térmica foram obtidas por meio de questionários desenvolvidos com base na norma internacional ISO 10551 (ISO, 1995). Os questionários foram aplicados durante o horário de monitoramento das variáveis climáticas. As variáveis pessoais levantadas foram sexo, idade, altura, peso, tempo de residência na cidade (fator aclimatação) e vestimenta, além das variáveis sobre percepção térmica. Todos os dados foram utilizados para o cálculo dos índices de conforto PMV e PET, com exceção do tempo de residência em Curitiba, que serviu como critério de exclusão, quando inferior a 6 meses.

Estudos como o de Matzarakis, Rutz e Mayer (2007) têm demonstrado a importância da temperatura radiante média, principalmente durante condições meteorológicas providas de sol, para a determinação dos índices de conforto. Dessa forma, embora a temperatura do ar seja relevante para a determinação dos níveis de conforto térmico, escolheu-se a temperatura radiante média como parâmetro para a análise de conforto térmico. A partir dos dados coletados, são adotados neste artigo os procedimentos a seguir descritos:

(a) comparações entre dados de temperatura radiante média versus níveis de conforto, minuto a minuto, para dias considerados comparáveis. Para a seleção desses dias específicos, utilizou-se como critério a diferença de radiação entre os pares de medição, segundo a Equação 1. O resultado é dado em diferenças percentuais entre o total de radiação solar incidente nos pares de medição.

$\%$ VARIAÇÃO $=\left[\left(\Sigma \operatorname{Ig}_{2}-\Sigma \operatorname{Ig}_{1}\right) / \Sigma \operatorname{Ig}_{2}\right] \times 100 \quad$ Eq.1

Onde:

$\Sigma \operatorname{Ig} 2$ : o total de radiação medido na estação 2; e

乏Ig1: o total de radiação medido na estação 1 .
Sendo considerados os dados do período de monitoramento das $11 \mathrm{~h} 01 \mathrm{~min}$ às $15 \mathrm{~h} 00 \mathrm{~min}$.

Para os dias com diferença de radiação entre os pontos inferior a 30\%, foram traçados gráficos relacionando a diferença de temperatura radiante média entre os pontos (estação 2- estação 1) e o índice de conforto, calculado no programa RayMan para o homem padrão. A escolha do índice de conforto utilizado nesta análise partiu do critério do índice (PMV ou PET) com melhor correlação com a sensação real. Nesta análise utiliza-se o homem padrão por ser possível a análise de minuto a minuto, considerando, também, que os minutos de coleta de questionários divergem em cada estação, inviabilizando a utilização da sensação real.

O valor de referência, $30 \%$, foi determinado em função dos valores de radiação encontrados nos 13 dias de medição. Em seguida, foram comparados, entre os pares de medição, os níveis de conforto calculado e a sensação real;

(b) verificação da relação entre o FVC de cada ponto e a diferença média entre a temperatura radiante média obtida in loco e a temperatura do ar da estação de referência $(\Delta T r m-T)$, considerando as situações de verão (medição de janeiro até maio) e inverno (medição de junho até agosto). Para que fosse possível a divisão nesses dois grupos, foram selecionados apenas os pontos monitorados em ambas as situações (pontos 2, 3, 4, 7, 10 e 14), sendo descartados os demais pontos (pontos 5, 6a, 6b, 8, 9, 13, 16, 17 e 18); e

(c) interpretação da incidência solar em cada ponto, por meio de cartas solares plotadas sobre as imagens olhos de peixe. Ressalta-se que tanto as fotos olho de peixe como as cartas solares utilizadas possuem projeção equidistante, sendo as trajetórias solares traçadas individualmente para cada dia de medição com o auxílio do programa RayMan.

\section{Resultados}

Uma vez que a análise climatológica de espaços abertos abrange uma diversidade de variáveis climáticas, sendo uma das mais impactantes a radiação solar global, buscaram-se entre os dias de monitoramento aqueles com menor diferença de intensidade de radiação solar incidente entre os pontos (Equação 1), sendo de $30 \%$ o valor de referência. $\mathrm{O}$ resultado, em porcentagem, pode ser visualizado na Tabela 3.

Os pares com menores diferenças de radiação incidente foram, por ordem crescente dessas diferenças, os dos dias 09/01/2009, 06/05/2009, 09/06/2009 e 17/06/2009. Devido à ausência de 
dados relativos à velocidade do vento no dia 06/05/2009, descartaram-se essas medições, e optou-se por analisar os outros três dias. As análises foram procedidas a partir da hipótese de que, em condições diurnas, pontos com maiores valores de FVC apresentem temperaturas radiantes médias mais elevadas devido à maior exposição das superfícies urbanas à radiação solar, com consequente impacto nos níveis de conforto obtidos.
Para a definição do índice de conforto a ser analisado em detalhe foram feitas inicialmente correlações entre os índices PMV e PET, calculados para o homem padrão, e a sensação real de conforto (Tabela 4). O total de entrevistados no dia 09/01/2009 foi de 81 pessoas (38 no ponto $2 \mathrm{e}$ 43 no ponto 7); no dia 09/06/2009 obteve-se um total de 90 respondentes (56 no ponto 17 e 34 no ponto 18); e no dia 17/06/2009 foram obtidas 66 respostas (36 no ponto 6 e 30 no ponto 2 ).

Tabela 3 - Diferenças percentuais de radiação solar incidente entre os pares de medição

\begin{tabular}{|c|c|c|c|c|c|}
\hline Data & Ponto & FVC & $\begin{array}{l}\text { Média de Trm } \\
{ }^{\circ} \mathrm{C}\end{array}$ & $\begin{array}{l}\text { Total de radiação* } \\
\qquad \mathrm{W} / \mathrm{m}^{2}\end{array}$ & $\begin{array}{c}\text { Percentual de diferença } \\
\text { de radiação solar } \\
\text { incidente } \%\end{array}$ \\
\hline \multirow{2}{*}{ 09/01/2009 } & 2 & 0,20 & 45,8 & 2449 & \multirow{2}{*}{9} \\
\hline & 7 & 0,39 & 48,0 & 2696 & \\
\hline \multirow{2}{*}{$25 / 03 / 2009$} & 10 & 0,30 & 29,5 & 731 & \multirow{2}{*}{65} \\
\hline & 3 & 0,32 & 45,4 & 2083 & \\
\hline \multirow{2}{*}{$01 / 04 / 2009$} & 13 & 0,22 & 29,2 & 662 & \multirow{2}{*}{-41} \\
\hline & 2 & 0,20 & 38,7 & 469 & \\
\hline \multirow{2}{*}{ 08/04/2009 } & 4 & 0,34 & 45,7 & 1859 & \multirow{2}{*}{-43} \\
\hline & 9 & 0,29 & 37,4 & 1297 & \\
\hline \multirow{2}{*}{ 06/05/2009 } & 4 & 0,34 & 31,2 & 2006 & \multirow{2}{*}{18} \\
\hline & 14 & 0,55 & 50,1 & 2440 & \\
\hline \multirow{2}{*}{ 03/06/2009 } & 4 & 0,34 & 32,9 & 1693 & \multirow{2}{*}{36} \\
\hline & 14 & 0,55 & 33,9 & 2626 & \\
\hline \multirow{2}{*}{ 05/06/2009 } & 10 & 0,30 & 19,7 & 183 & \multirow{2}{*}{43} \\
\hline & 5 & 0,22 & 22,2 & 319 & \\
\hline \multirow{2}{*}{ 09/06/2009 } & 17 & 0,21 & 29,1 & 848 & \multirow{2}{*}{33} \\
\hline & 18 & 0,30 & 29,0 & 1261 & \\
\hline \multirow{2}{*}{ 17/06/2009 } & $6 a$ & 0,26 & 14,5 & 160 & \multirow{2}{*}{28} \\
\hline & 2 & 0,20 & 15,9 & 222 & \\
\hline \multirow{2}{*}{ 19/06/2009 } & 3 & 0,32 & 19,7 & 253 & \multirow{2}{*}{63} \\
\hline & 7 & 0,39 & 24,4 & 678 & \\
\hline \multirow{2}{*}{$13 / 07 / 2009$} & 8 & 0,37 & 27,9 & 966 & \multirow{2}{*}{60} \\
\hline & 16 & 0,38 & 31,1 & 2411 & \\
\hline
\end{tabular}

Nota: *Total de radiação global (solar difusa, solar direta e refletida pelo entorno) recebida por hora em cada ponto.

Tabela 4 - Correlações (R) entre os índices de conforto e a sensação real de conforto

\begin{tabular}{cccc}
\hline Data & Ponto & PMV x Real & PET x Real \\
\hline \multirow{2}{*}{$09 / 01 / 2009$} & 2 & 0,86 & 0,91 \\
\cline { 2 - 4 } & 7 & 0,44 & 0,45 \\
\hline \multirow{2}{*}{$09 / 06 / 2009$} & 17 & 0,90 & 0,87 \\
\cline { 2 - 4 } & 18 & 0,98 & 0,98 \\
\hline \multirow{2}{*}{$17 / 06 / 2009$} & 6 & 0,69 & 0,08 \\
\cline { 2 - 4 } & 2 & 0,79 & 0,09 \\
\hline
\end{tabular}




\section{Relação entre os índices e a sensação real}

No dia 09/01/2009, dia com temperaturas mais altas, nota-se que o índice PET apresenta melhor correlação do que o PMV nos dois pontos monitorados. Situação oposta acontece nos dias com temperaturas mais baixas, com o PMV apresentando melhor correlação com a sensação real do que o PET, principalmente no dia $17 / 06 / 2009$.

As Figuras 5, 6 e 7 correspondem às diferenças entre os valores de Trm de cada ponto $(\Delta \mathrm{Trm})$ e os valores dos índices de conforto com melhor correlação com essa variável, considerando o período de monitoramento.

\section{9/01/2009}

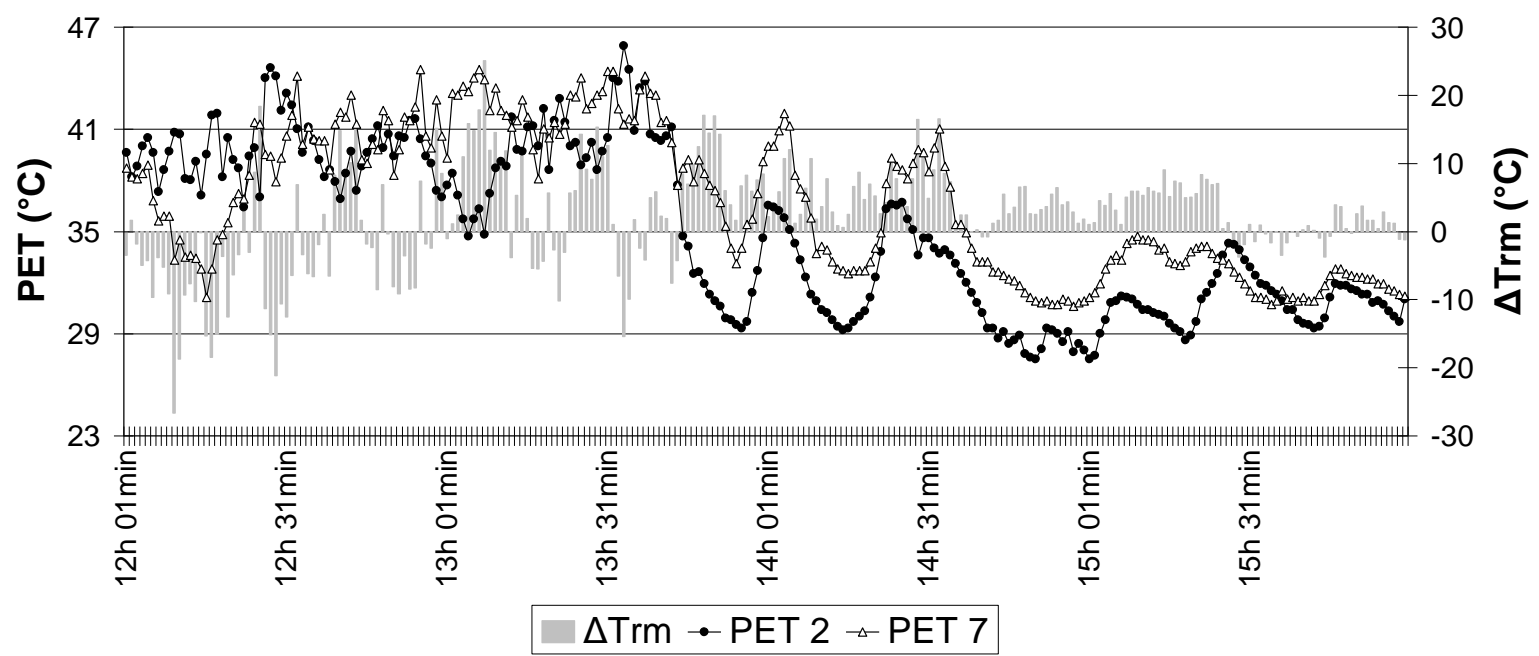

Figura 5 - Relação entre a diferença de Trm (ponto 7 - ponto 2) e o índice PET

\section{9/06/2009}

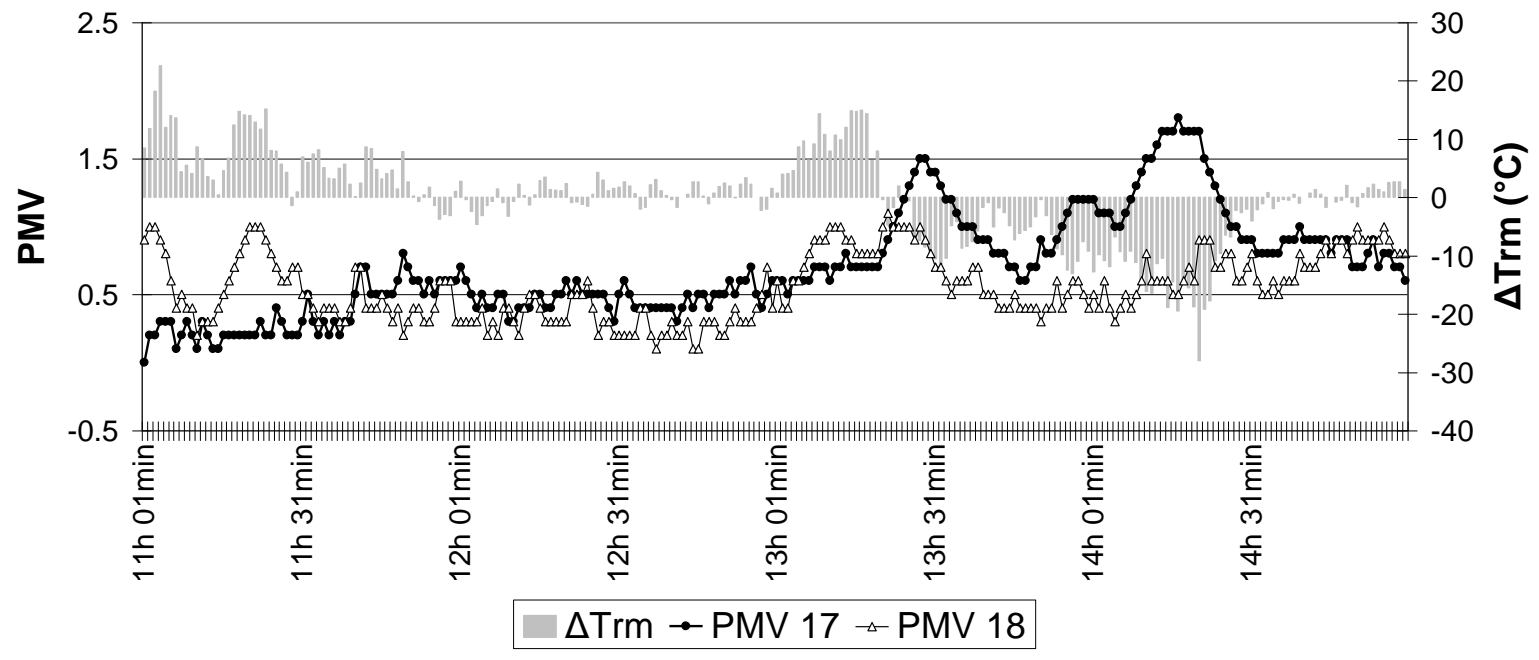

Figura 6 - Relação entre a diferença de Trm (ponto 18 - ponto 17) e o índice PMV 


\section{$17 / 06 / 2009$}

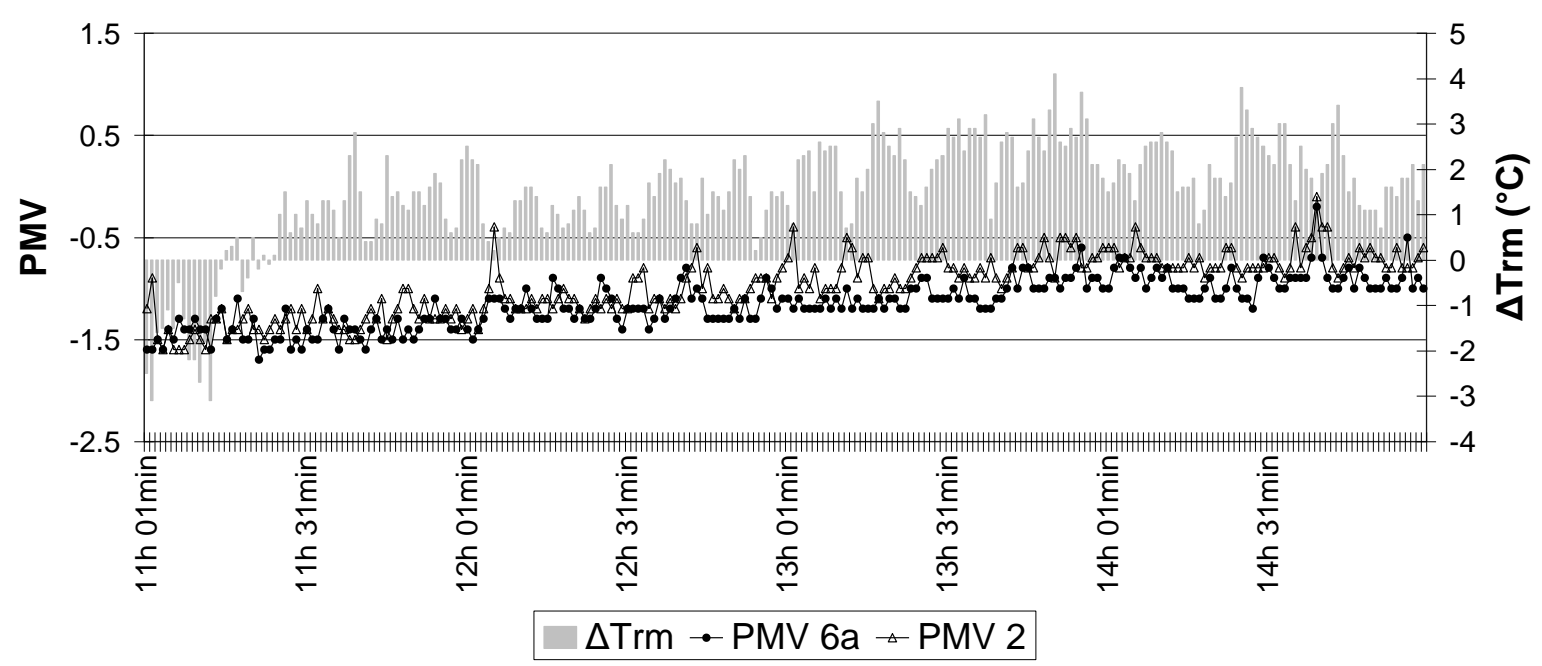

Figura 7 - Relação entre a diferença de Trm (ponto 6a - ponto 2) e o índice PMV

No dia 09/01/2009, as medições ocorreram no ponto 2 (FVC 0,20) e no ponto 7 (FVC 0,39). Nota-se a seguinte relação entre os valores do PET com a Trm: quando a Trm é mais alta no ponto 7, a diferença é positiva e os valores do PET nesse ponto são maiores, como pode ser verificado no horário das 13h05min (Figura 5). De maneira análoga, quando a temperatura do ponto 2 é mais alta, diferença negativa, os valores do PET para esse ponto são maiores, como observado no horário das $12 \mathrm{~h} 06 \mathrm{~min}$ até às $12 \mathrm{~h} 30 \mathrm{~min}$. Ao longo do período de monitoramento, a predominância de temperaturas mais altas no local com menor obstrução à abóbada celeste (ponto 7) é nítida, ocorrendo uma inversão de Trm mais considerável no período próximo às $12 \mathrm{~h} 20 \mathrm{~min}$. Em relação ao PET nos pontos 2 e 7 , durante a maior parte do dia, os valores ficaram na faixa entre $27,5^{\circ} \mathrm{C}$ e $45,9^{\circ} \mathrm{C}$, com média de $35^{\circ} \mathrm{C}$ no período monitorado.

No dia 09/06/2009, a Trm foi mais alta no ponto 17 (FVC 0,21) até às 13h20min (Figura 6). Após esse horário, o ponto 18 (FVC 0,30) obteve maiores valores de Trm. Nota-se que, no período das $12 \mathrm{~h} 00 \mathrm{~min}$ até aproximadamente às $13 \mathrm{~h} 00 \mathrm{~min}$, a diferença nos valores de Trm é pequena, refletindo em diferenças de PMV pouco acentuadas. Valores mais significativos são encontrados logo no início das medições, com maiores oscilações de temperatura no ponto 17 , e no período da tarde, quando a temperatura é mais alta no ponto 18 .
A Figura 7 apresenta a relação entre o PMV e a Trm nos pontos 6a (FVC 0,26) e 2 (FVC 0,20) para a medição do dia 17/06/2009. Os maiores valores de Trm foram observados no ponto com menor obstrução à abóboda (em Relação entre FVC e diferenças entre temperatura radiante média e temperatura do ar são apontados fatores que podem explicar esse fato). De forma geral, os valores da Trm estão bem próximos, com diferenças mais acentuadas em momentos específicos, como, por exemplo, às 12h06min.

As análises seguintes referem-se à comparação entre os graus de estresse térmico calculados pelos índices PMV e PET e a sensação real obtida por meio dos questionários.

No dia 09/01/2009 o estresse térmico foi para calor (Figura 8 e 9). Percebe-se que os índices PMV e PET, calculados para o homem padrão, apresentaram valores próximos entre si, tanto para o ponto 2 (FVC 0,20 ) como para o ponto 7 (FVC 0,39). O ponto 2, local com menor valor de FVC, apresentou maior variação nos graus de estresse térmico que o ponto 7 , com predominância na faixa de moderado estresse ao calor (mais de $40 \%$ ). Mais desconfortável termicamente que o ponto 2, o ponto 7 apresentou maior concentração de votos calculados na faixa de extremo estresse ao calor (mais de $35 \%$ ). 


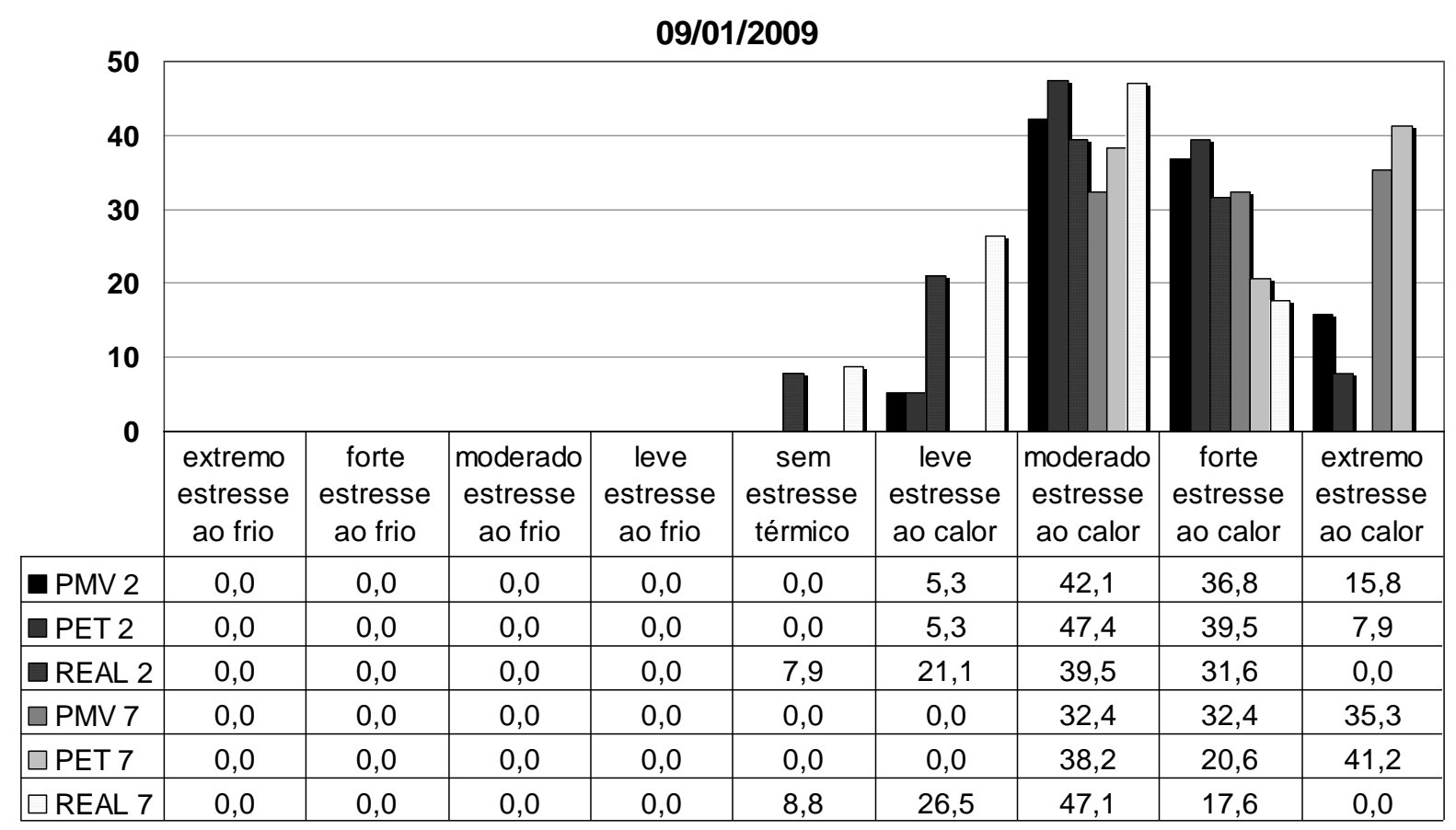

Figura 8 - Grau de estresse térmico entre os pares de medição 2 e 7

\section{9/01/2009}

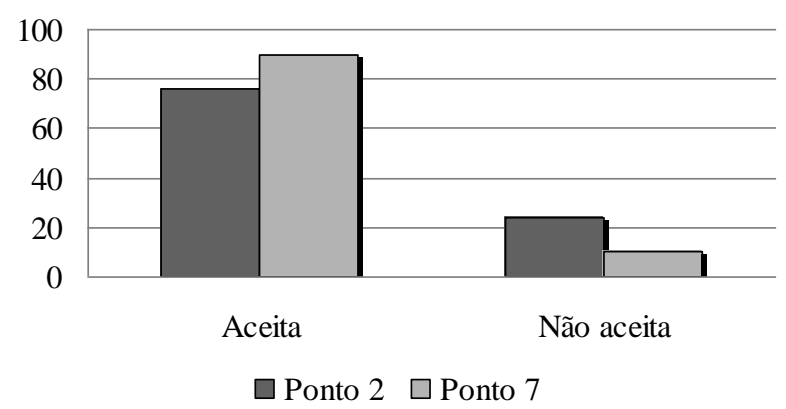

Figura 9 - Histograma de aceitabilidade térmica para o dia 9/01/2009

Considerando a sensação térmica real dos transeuntes, nota-se uma diferença significativa entre os votos calculados e os reais. A sensação real dos transeuntes, nos pontos 2 e 7 , variou da faixa de conforto até o grau de forte estresse ao calor, enquanto os índices PMV e PET parecem superestimar os valores ${ }^{3}$, atingindo a faixa de extremo estresse térmico. Tal fato comprova o que afirmam Nicol et al. (2006) e Nikolopoulou e Steemers (2003) em relação à sensação de conforto e à maior tolerância a variações térmicas em espaços externos. Os resultados encontrados parecem evidenciar que a sensação de desconforto esperada não ocorre na mesma intensidade com a amostra de indivíduos. O histograma de

\footnotetext{
${ }^{3}$ Ressalta-se que os índices de conforto utilizados foram desenvolvidos para a realidade climática do hemisfério Norte, podendo esse fato ter influenciado a diferença observada entre a resposta real e a calculada.
}

aceitabilidade térmica para a amostra de indivíduos confirma que a grande maioria aceita aqueles ambientes térmicos (Gráfico 5).

Na Figura 10, referente à situação de frio, percebese que, em comparação com a sensação real, os índices PET e PMV subestimam a variação de votos nos graus de estresse fisiológico, principalmente o PMV. A análise da aceitabilidade térmica desses pontos (Figura 11) mais uma vez comprova a maior aceitabilidade de condições desconfortáveis em ambientes externos, principalmente quando se considera que o PMV é um índice indicado para ambientes internos. No ponto 17 , considerando o PMV, a predominância de votos foi em leve estresse ao calor $(73,2 \%)$, enquanto para o índice PET a maioria esteve em conforto (62,5\%). Na sensação real, 35,7\% estiveram em conforto, e 44,6\% em leve estresse ao calor. No ponto 18 , para os índices térmicos e 
para a sensação real, a predominância foi em conforto (mais de 64\% em todos os casos). No ponto 17 (FVC 0,21), a sensação real abrangeu a faixa de moderado estresse ao frio até moderado estresse ao calor, com tendência para desconforto para calor. No ponto 18 (FVC 0,30), a sensação real variou da ausência de estresse térmico até forte estresse térmico. Ainda que a diferença de FVC entre os pontos não seja muito significativa, em situação de temperaturas mais baixas como no dia monitorado, o ponto com maior valor de FVC, ponto 18 , apresentou maior conforto térmico que o ponto 17 .

O índice PMV (Figura 12) para o homem padrão no ponto 6 (FVC 0,26$)$ apresentou maior número de votos percentuais em leve estresse ao frio $(91,7 \%)$, enquanto para o índice PET a predominância foi em moderado estresse ao frio
$(72,2 \%)$. No entanto, a concentração de votos para a sensação real foi em leve estresse ao frio $(41,7 \%)$, com considerável porcentagem em conforto $(38,9 \%)$. A maior tolerância dos dados reais em relação aos preditos é mostrada no histograma de frequências para a data (Figura 13). Caso semelhante ocorreu no ponto 2 (FVC 0,20), no qual $90 \%$ dos votos foram de leve estresse ao frio para o índice PMV e 83,3\% de votos em moderado estresse ao frio considerando o índice PET, valores que se diferenciam da sensação real, na qual a predominância de votos foi em leve estresse ao frio $(46,7 \%)$ e em conforto $(40,0 \%)$. Devido ao fato de os pares monitorados possuírem pouca diferença nos valores de FVC, ocorreu pouca diferença nos valores de estresse térmico entre os pontos.

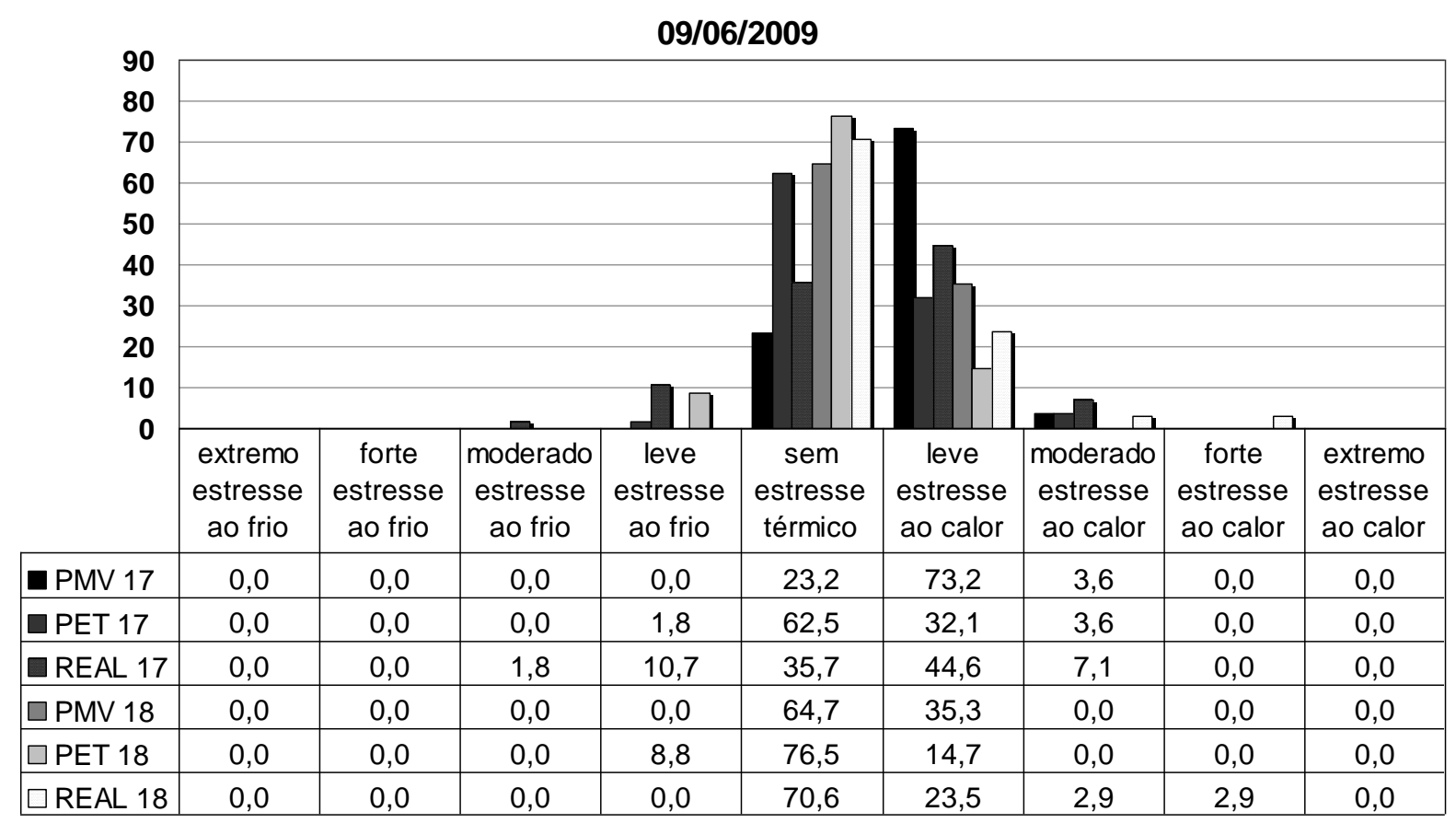

Figura 10 - Grau de estresse térmico entre os pares de medição 17 e 18

09/06/2009

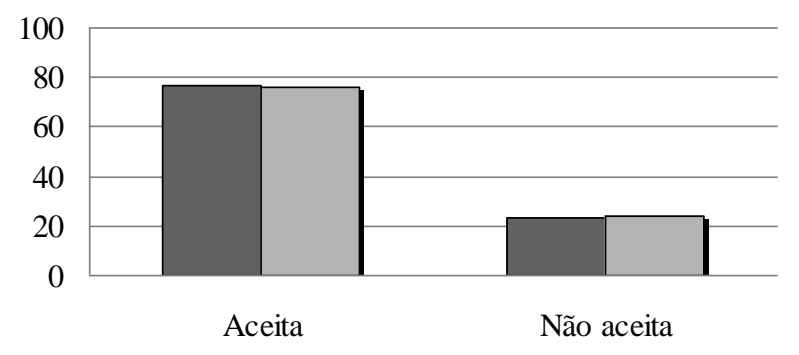

Ponto $17 \quad \square$ Ponto 18

Figura 11 - Histograma de aceitabilidade térmica para o dia 9/06/2009 


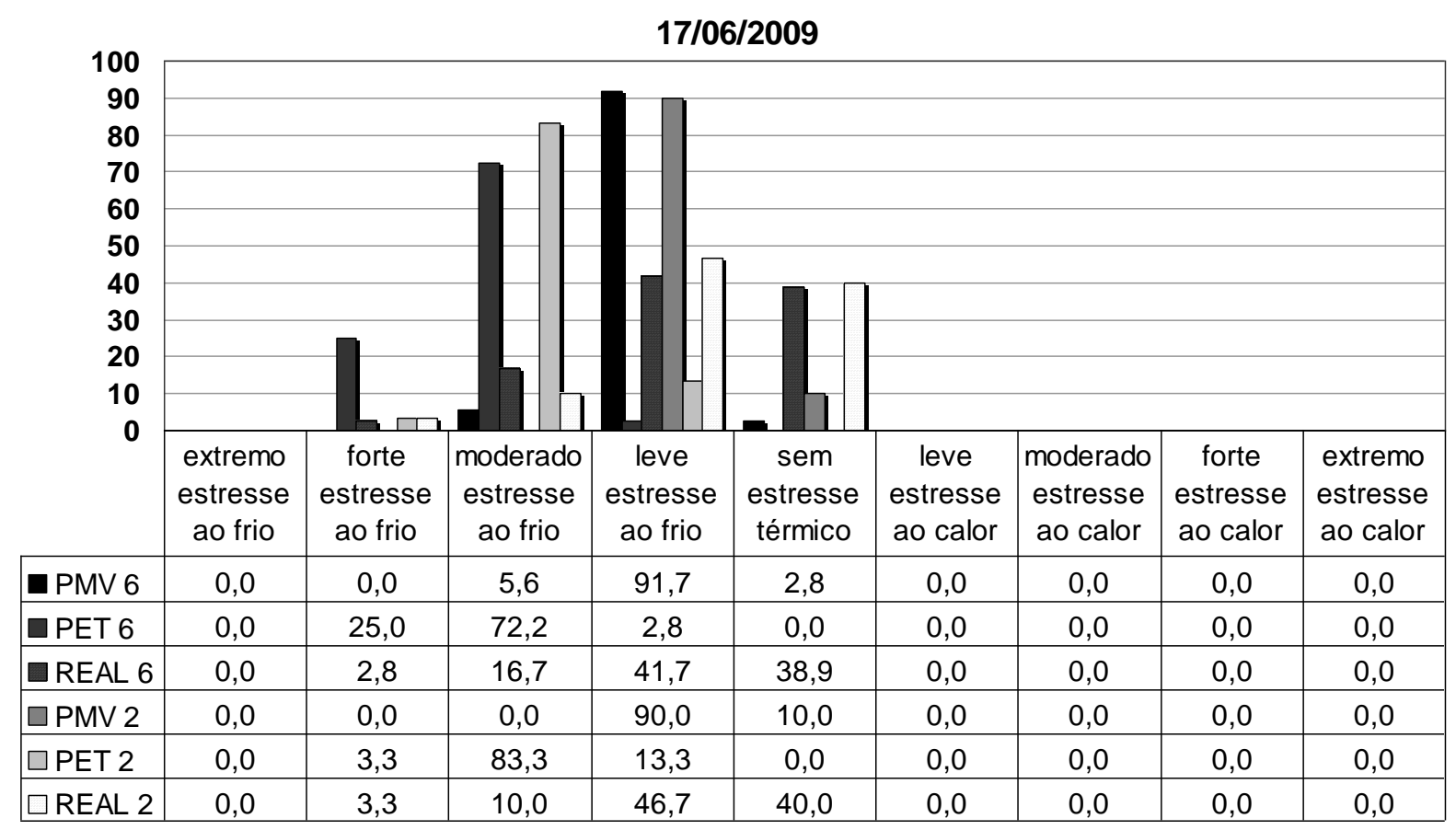

Figura 12 - Grau de estresse térmico entre os pares de medição 6 e 2

\section{$17 / 06 / 2009$}

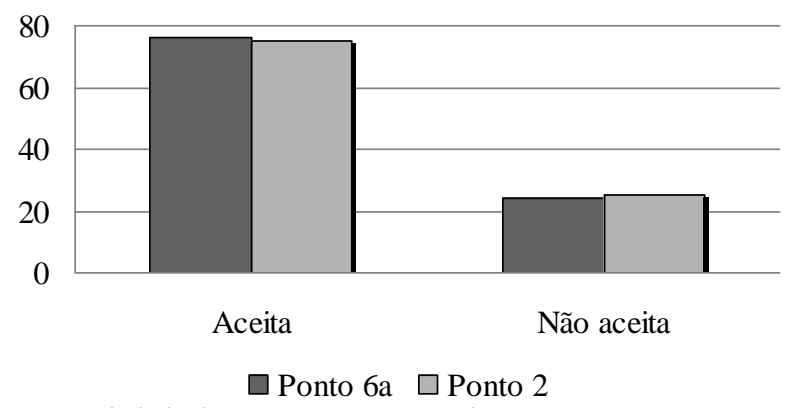

Figura 13 - Histograma de aceitabilidade térmica para o dia 17/06/2009

\section{Relação entre FVC e diferenças entre temperatura radiante média e temperatura do ar}

As Figuras 14 e 15 apresentam a relação entre o FVC de cada ponto e a diferença média diária da Trm obtida in loco com a temperatura do ar da estação de referência $(\Delta \mathrm{Trm}-\mathrm{T})$, considerando as situações de "verão" (medição de janeiro até maio) e "inverno" (medição de junho até agosto). Os pontos considerados nesta análise são aqueles que foram monitorados nessas duas situações (Tabela 5).

Conforme as Figuras 14 e 15, nota-se que o coeficiente de determinação é baixo nos dois casos, apresentando praticamente o mesmo valor tanto em dias com temperaturas mais altas $(0,44)$ como em dias com temperaturas mais baixas $(0,45)$.

Considerando os dados obtidos e as análises feitas para este estudo, o FVC, isoladamente, não parece ser o fator determinante do microclima urbano. No entanto, observa-se nos gráficos de dispersão acima que as linhas de tendência são ascendentes, isto é, conforme aumenta o valor de FVC, aumentam os valores referentes às diferenças entre a temperatura radiante média obtida in loco e a temperatura do ar da estação de referência $(\Delta$ TrmT). Ponderando que o microclima urbano resulta da interação de diversas variáveis, realizou-se a análise entre a quantidade de radiação recebida em cada pondo e o FVC, com o objetivo de analisar a influência da radiação solar nos níveis de conforto térmico. 


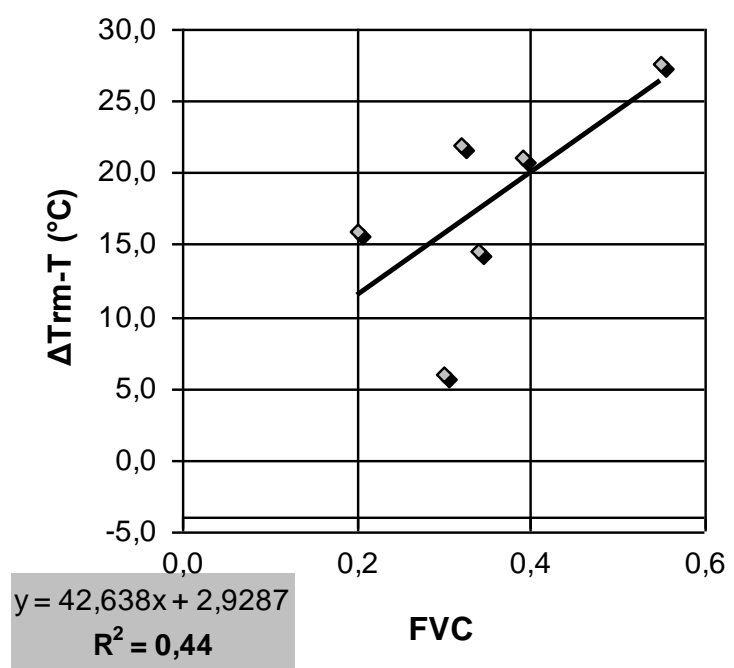

Figura 14 - Grau de dispersão entre FVC e $\Delta$ Trm-T - situação de verão

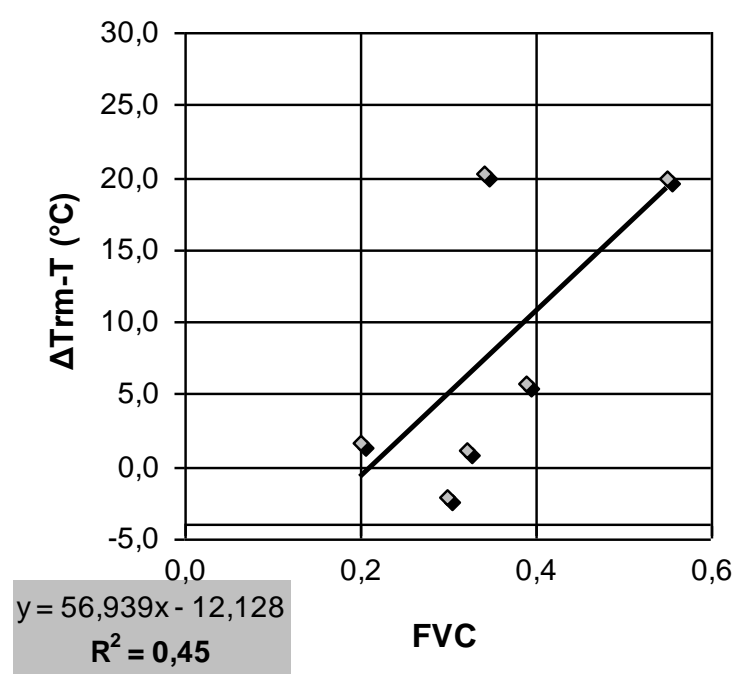

Figura 15 - Grau de dispersão entre FVC e $\Delta$ Trm-T - situação de inverno

Tabela 5 - Valores de $\Delta \operatorname{Trm}-\mathrm{T}$ nas situações de verão e inverno

\begin{tabular}{cccc}
\hline Ponto & FVC & $\begin{array}{c}\Delta \text { Trm-T } \\
\text { verão }\end{array}$ & $\begin{array}{c}\Delta \text { Trm-T } \\
\text { inverno }\end{array}$ \\
\hline 2 & 0,20 & 15,9 & 1,7 \\
3 & 0,32 & 21,9 & 1,2 \\
4 & 0,34 & 14,6 & 20,3 \\
7 & 0,39 & 21,0 & 5,8 \\
10 & 0,30 & 6,0 & $-2,2$ \\
14 & 0,55 & 27,6 & 20,0 \\
\hline
\end{tabular}

\section{Relação entre a radiação solar e o FVC}

A temperatura radiante média é uma importante variável no que diz respeito aos índices de conforto térmico, estando diretamente relacionada à radiação solar. Em condições diurnas, o fator de visão do céu, quando analisado como um parâmetro isolado, não é capaz de predizer as condições térmicas de determinado local, uma vez que a quantidade de radiação solar influencia sobremaneira os valores de Trm. No entanto, uma análise conjunta do FVC e da radiação solar pode fornecer resultados mais precisos quanto ao nível de conforto térmico auferido. 
A Figura 16 mostra a trajetória solar do ponto 2 (FVC 0,20) e do ponto 7 (FVC 0,39), monitorados no dia 09/01/2009. Nota-se que o ponto 2 recebe sol das 9h00min até as $16 \mathrm{~h} 00 \mathrm{~min}$. Considerandose o período de medição, das $11 \mathrm{~h} 01 \mathrm{~min}$ até as $15 \mathrm{~h} 00 \mathrm{~min}$, o total de radiação incidente nesse ponto foi de $2.449 \mathrm{~W} / \mathrm{m}^{2}$. No ponto 7 , o período de incidência de radiação solar abrange o intervalo das $8 \mathrm{~h} 00 \mathrm{~min}$ até as $16 \mathrm{~h} 00 \mathrm{~min}$, sendo considerável o somatório de radiação incidente no período de monitoramento $\left(2.696 \mathrm{~W} / \mathrm{m}^{2}\right)$. Nesses dois pontos, os valores de FVC são diferentes, e o ponto menos obstruído, ponto 7 , recebe uma hora de sol a mais que o ponto 2 .

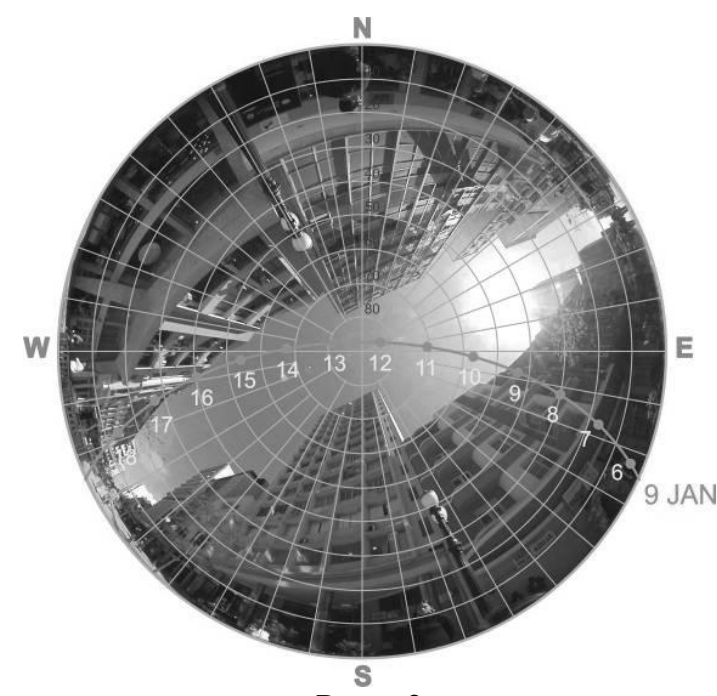

Ponto 2
Os pontos 17 e 18 (Figura 17) apresentam orientação em relação ao norte distinta dos demais pontos (NW-SE). O ponto 18 (FVC 0,30) é menos obstruído que o ponto 17 (FVC 0,21). As medições nesses pontos ocorreram no dia 09/06/2009. O ponto 17 recebe radiação solar por, aproximadamente, $40 \mathrm{~min}$ (período das $13 \mathrm{~h} 50 \mathrm{~min}$ até as $14 \mathrm{~h} 30 \mathrm{~min}$ ), sendo o total de radiação de 848 $\mathrm{W} / \mathrm{m}^{2}$. O ponto 18 recebe radiação solar no intervalo das $11 \mathrm{~h} 00 \mathrm{~min}$ até as $12 \mathrm{~h} 20 \mathrm{~min} \mathrm{e}$, posteriormente, no intervalo das $14 \mathrm{~h} 30 \mathrm{~min}$ até o final do monitoramento. No período de medição, a quantidade de radiação solar foi de $1.261 \mathrm{~W} / \mathrm{m}^{2}$.

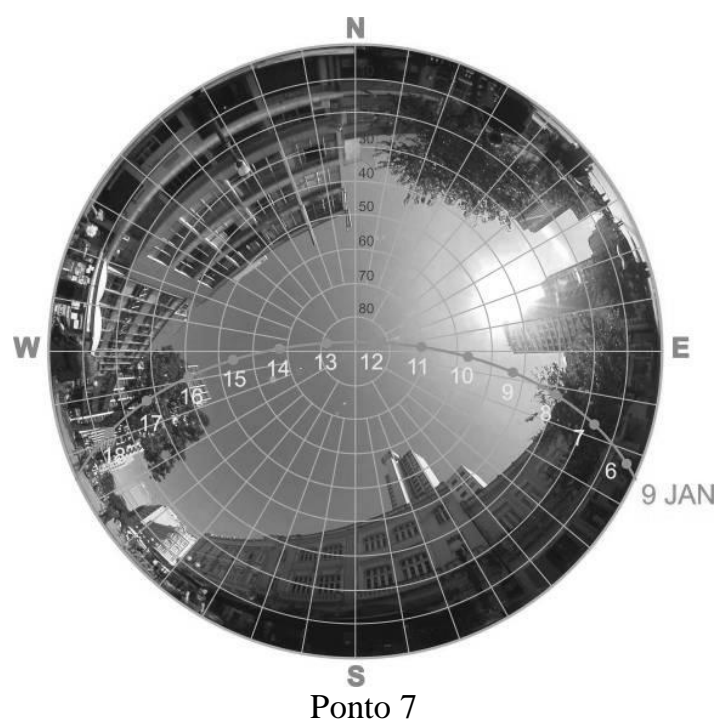

Figura 16 - Foto olho de peixe com carta solar para os pontos 2 e 7 Fonte: Minella (2009).

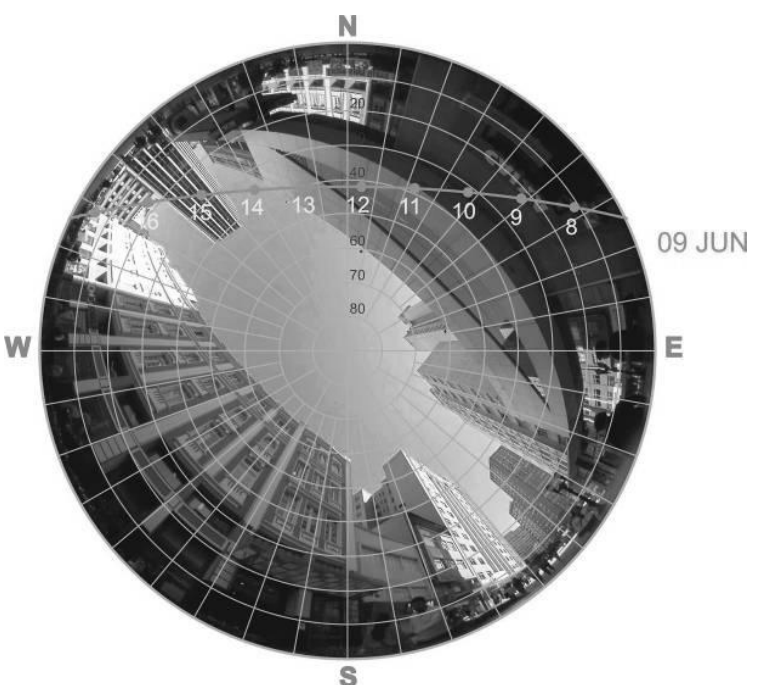

Ponto 17

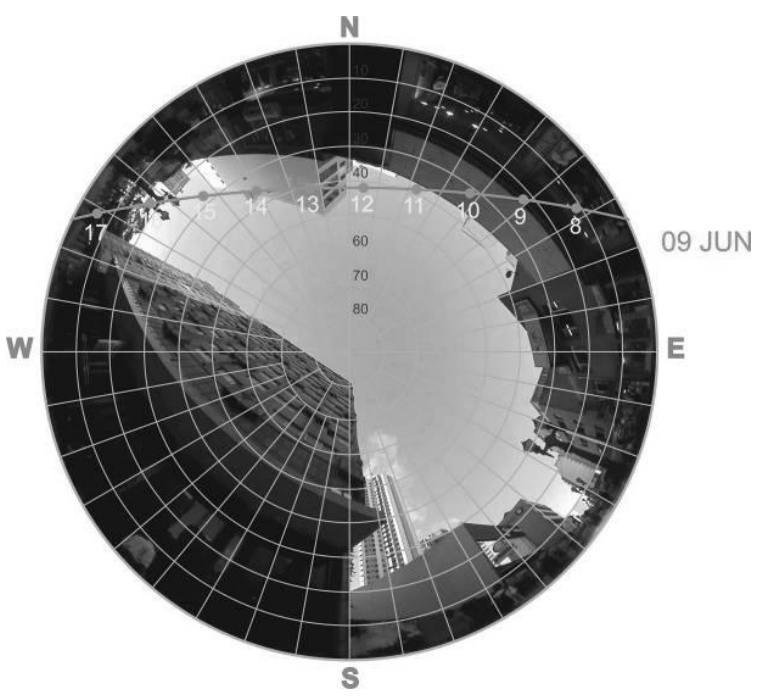

Ponto 18

Figura 17 - Foto olho de peixe com carta solar para os pontos 17 e 18 Fonte: Minella (2009). 

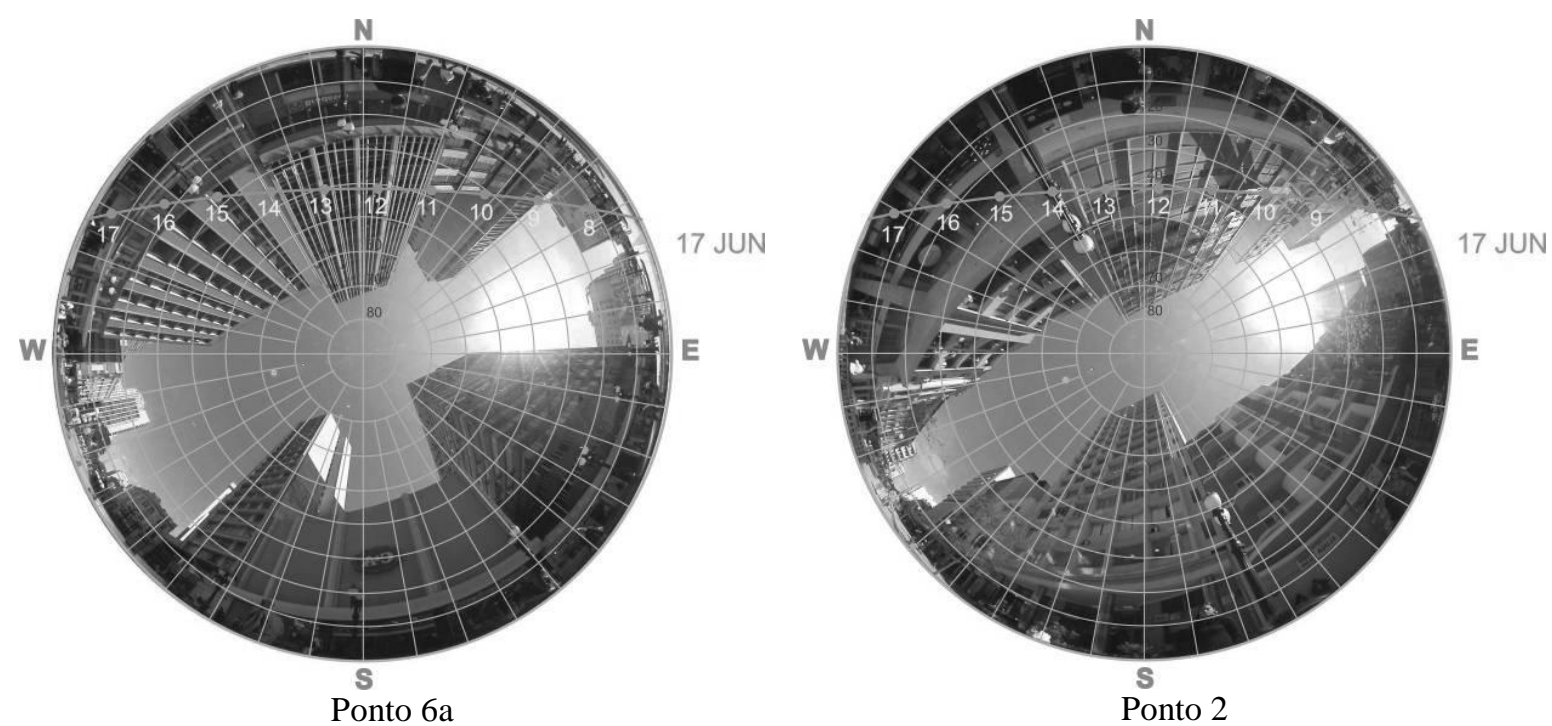

Figura 18 - Foto olho de peixe com carta solar para os pontos $6 \mathrm{a}$ e 2

Fonte: Minella (2009).

O ponto 6a (FVC 0,26) e o ponto $2($ FVC 0,20$)$ foram locais de medição no dia 17/06/2009 (Figura 18). Verifica-se que durante todo o período de monitoramento ambos permanecem na sombra, sem influência direta da radiação solar.

A diferença de radiação solar incidente nos pontos $6 \mathrm{a}\left(\mathrm{Ig}=160 \mathrm{~W} / \mathrm{m}^{2}\right)$ e $2\left(\mathrm{Ig}=222 \mathrm{~W} / \mathrm{m}^{2}\right)$ é de $28 \%$, sendo essa variável mais alta no ponto 2 . Três fatores podem ter influenciado o ambiente térmico nesses pontos: a presença de uma fonte d'água próximo à estação meteorológica no ponto 6 ; a contribuição da abóbada celeste (radiação difusa); e as influências das reflexões da radiação recebida na área vertical edificada (em função do albedo).

$\mathrm{Na}$ análise da carta solar sobreposta à foto olho de peixe, é atestado que, embora o FVC possa auxiliar na definição da forma urbana, esse é um parâmetro limitado para descrever as irregularidades e os meandros da geometria urbana, muito embora isso seja um avanço quando comparado à simplificação da relação $\mathrm{H} / \mathrm{W}$, pois a radiação solar pode atingir de maneiras distintas pontos com valores de FVCs semelhantes. Assim, a questão da acessibilidade solar adquire grande importância em se tratando de estudos de conforto térmico em espaços abertos.

\section{Considerações finais}

Os resultados apresentados apontam para uma pequena influência do efeito diurno do FVC no microclima em dias com temperaturas mais altas $\left(R^{2}=0,44\right)$ e mais baixas $\left(R^{2}=0,45\right)$. De acordo com a revisão apresentada, diversos estudos apontam que o FVC tem pouca influência para a determinação do microclima (ELIASSON, 1996; UPMANIS; CHEN, 1999; SOUZA, 2007), enquanto alguns outros estudos (UNGER, 2004; SVENSSON, 2004) mostram forte correlação. Essas divergências de resultados podem ser explicadas pelos diferentes métodos para a obtenção dos dados, diferentes números de pontos analisados, dias e horários de medição. Além disso, outras variáveis podem influenciar o microclima urbano. Apesar de os resultados para Curitiba não apresentarem forte correlação entre o FVC e o microclima, é possível verificar a existência de uma relação entre esses fatores.

No tocante aos índices de conforto térmico Voto Médio Estimado (PMV) e Temperatura Fisiológica Equivalente (PET), estes apresentaram maior correspondência entre si em dias com temperaturas mais altas. Embora não tenha sido verificado um padrão entre o FVC e a temperatura radiante média, pode-se dizer que há uma tendência em relação ao valor de FVC e a variável, isto é, à medida que o valor de FVC diminui, ou seja, à medida que há mais obstruções no entorno do ponto considerado, também diminuem os valores de temperatura radiante média. Nas análises dos níveis de conforto térmico, verificou-se que, em dias com temperaturas mais elevadas, pontos com menor obstrução da abóbada celeste, com maior valor de FVC, acarretam em maior desconforto por calor (indicando que localidades com maior FVC apresentam menores perdas térmicas durante $\mathrm{o}$ dia). No entanto, esses mesmos pontos podem apresentar melhor situação de conforto em dias com temperaturas mais baixas. Faz-se a ressalva de que o programa RayMan, utilizado no cálculo dos índices térmicos, considera um momento particular, ou seja, o programa não leva em conta o histórico térmico e a expectativa dos transeuntes. É 
necessário considerar, inclusive, que a comparação realizada entre os índices térmicos com a sensação real confronta as características do homem padrão com as características físicas reais dos transeuntes.

Os resultados apontam, também, que em dias com temperaturas mais altas o índice de conforto com melhor correlação com a sensação real foi o PET, enquanto em dias com temperaturas mais baixas sugere-se utilizar o PMV. Tal fato comprova que, em ambientes externos, as pessoas têm maior tolerância a variações térmicas que em ambientes internos. Isso é reforçado pela diferença maior encontrada entre a sensação real e o PMV, índice concebido para ambientes internos. Deve-se ressaltar que essa maior tolerância térmica dos transeuntes traz consigo maiores oportunidades de adaptação (SPAGNOLO; DE DEAR, 2003), como, por exemplo, procurar regiões ao sol ou à sombra ao se caminhar pela rua de pedestres.

A temperatura radiante média possui relação direta com a quantidade de radiação solar incidente, o que demonstra a importância do desenho urbano para a determinação dos níveis de conforto. $\mathrm{Na}$ análise da carta solar, foi possível verificar uma limitação do FVC, pois esse parâmetro quantifica a área de céu disponível, não havendo relação direta com a questão do acesso solar. Assim, a radiação solar pode atingir de maneiras distintas pontos com valores de FVC semelhantes. Verifica-se, então, que o impacto da geometria urbana no microclima e nos níveis de conforto térmico, quando analisado em conjunto com a questão da acessibilidade solar, pode oferecer resultados mais coerentes.

\section{Referências}

ASSOCIAÇÃO BRASILEIRA DE NORMAS TÉCNICAS. NBR 15220-3: desempenho térmico de edificações: parte 3: zoneamento bioclimático brasileiro e diretrizes construtivas para habitações unifamiliares de interesse social. Rio de Janeiro, 2005.

ACP - Associação Comercial Do Paraná. Calçadão da XV Vai Brilhar de Novo. 22 nov. 2007. Disponível em:

<http://www.acpr.com.br/index.php?a=novembro 2007.php>. Acesso em: 4 nov. 2009.

ANANIAN, P.; FONTES, M. S. G. de C.; SILVA, B. Avaliação Quanto ao Desempenho Térmico de Equipamento Urbano no Calçadão de Bauru. In: ENCONTRO NACIONAL DE CONFORTO NO AMBIENTE CONSTRUÍDO, 8., 2005, Maceió, AL. Anais... Maceió, AL: ENTAC, 2005. 1 CDROM.
BRUSANTI, G. N.; FONTES, M. S. G. C. Conforto Térmico em Espaços Públicos de Permanência: uma experiência na cidade de Bauru, SP. In: ENCONTRO NACIONAL DE CONFORTO NO AMBIENTE CONSTRUÍDO, 10., 2009, Natal, RN. Anais... Natal, RN: ENTAC, 2009. 1 CD-ROM.

\section{CAMPBELL SCIENTIFIC. Application Note:}

weather station siting and installation tools. Logan: Campbell Scientific, 1997.

CHAPMAN, L.; THORNES, J. E. Real-Time SkyView Factor Calculation and Approximation.

Journal of Atmospheric and Oceanic

Technology, v. 21, n. 5, p. 730-742, 2004.

CHAPMAN, L.; THORNES, J. E.; BRADLEY, A. V. Rapid Determination of Canyon Geometry Parameters for Use Surface Radiation Budgets. Theoretical and Applied Climatology, v. 69, n. 1/2, p. 81-89, 2001.

CHAPMAN, L. et al. Potential Applications of Thermal Fisheye Imagery in Urban Environments Geoscience and Remote Sensing Letters. IEEE Geoscience and Remote Sensing Letters, v. 4, n. 1, p. 56-59, 2007.

CORREA, E. N. et al. Evaluación del Factor de Visión de Cielo a partir del Procesamiento Digital de Imágenes Hemiesféricas: influencia de la configuración del canón urbano en la disponibilidad del recurso solar. Avances en Energías Renovables y Medio Ambiente, v. 9, n. 1, p. 43-48, 2005.

DACANAL, C. et al. Conforto Térmico em Espaços Livres Públicos: estudo de caso em Campinas, SP. In: ENCONTRO NACIONAL DE CONFORTO NO AMBIENTE CONSTRUÍDO, 10., 2009, Natal, RN. Anais... Natal, RN: ENTAC, 2009. 1 CD-ROM.

ELIASSON, I. Urban Nocturnal Temperatures, Street Geometry and Land Use. Atmospheric Environment, v. 30, n. 3, p. 379-392, 1996.

FANGER, P. O. Thermal Comfort. Florida: Robert E. Krieger Publishing Company, 1982.

HÖPPE, P. The Physiological Equivalent Temperature: a index for the biometeorological assessment of the thermal environment. International Journal of Biometeorology, n. 43. p. 71-75, 1999.

\section{INSTITUTO BRASILEIRO DE GEOGRAFIA E} ESTATÍSTICA. Censo 2000: resultado do universo. Disponível em: <http://www.ibge.gov.br/home/estatistica/populaca o/contagem2007/defaulttab.shtm>. Acesso em: 21 jan. 2009. 
INTERNATIONAL ORGANIZATION FOR STANDARDIZATION. ISO 10551: ergonomics of the thermal environment: assessment of the influence of the thermal environmet using subjetive judgement scales. Switzerland, 1995.

INTERNATIONAL ORGANIZATION FOR STANDARDIZATION. ISO 7726: ergonomics of the thermal environment: instruments of measuring physycal quantities. Switzerland, 1998.

\section{INTERNATIONAL ORGANIZATION FOR} STANDARDIZATION. ISO 7730: ergonomics of the thermal environment: analytical determination and interpretation of thermal comfort using calculation of the PMV and PPD indices and local thermal comfort criteria. Switzerland, 2005.

INTERNATIONAL ORGANIZATION FOR STANDARDIZATION. ISO 8896: ergonomics of the thermal environment: determination of metabolic rate. Switzerland, 2004.

IPPUC - Instituto de Pesquisa e Planejamento Urbano de Curitiba. Curitiba em Ddos. 2009. Disponível em:

<http://ippucnet.ippuc.org.br/Bancodedados/Curiti baemdados/Curitiba_em_dados_Pesquisa.asp>. Acesso em: 01 dez. 2009.

JOHNSON, G. T.; WATSON, I. D. The Determination of View-Factors in Urban Canyons. Journal of Applied Climate and Meteorology, v. 23, p. 329-335, 1984.

LAMBERTS, R.; ANDREASI, W. A. Tópicos Avançados de Conforto Térmico. Florianópolis, 2003. Disponível em:

<www.dec.ufms.br/lade/docs/cft/tact.pdf >. Acesso em: 5 ago. 2009.

LOIS, E.; LABAKI, L. C. Conforto Térmico em Espaços Externos: uma revisão. In: ENCONTRO NACIONAL DE CONFORTO NO AMBIENTE CONSTRUídO, 6., 2001, São Pedro. Anais... São Pedro: ANTAC, 2001.

MATZARAKIS, A.; RUTZ, F.; MAYER, H. Modelling Radiation Fluxes in Simple and Complex Environments: application of the RayMan model. International Journal Biometeorology, v. 51, p. 323-334, 2007.

MAYER, H.; MATZARAKIS, A. HumanBiometeorological Assessment of Urban Microclimates' Thermal Component. In: JAPANESE-GERMAN MEETINGS "KLIMAANALYSE FÜR DIE STADTPLANUNG”, 2. Toward Reconstruction in Kobe. 1998. Report of Research Center for Urban Safety and Security, Kobe University, Special Report, n. 1, p. 155-168. 1998.
MINELLA, F. O. Avaliação da Influência de Aspectos da Geometria Urbana Sobre Níveis de Conforto Térmico em Ruas de Pedestres de Curitiba. 2009. 163 f. Dissertação (Mestrado em Tecnologia) - Programa de Pós-Graduação em Tecnologia, Universidade Tecnológica Federal do Paraná, Curitiba, 2009.

MOIN, U. M.; TSUTSUMI, J. Rapid Estimation of Sky View Factor and Its Application to Human Environment. Journal of the HumanEnvironment System, v. 7, n. 2, p. 83-87, 2004.

MONTEIRO, L. M.; ALUCCI , M. P. Questões Teóricas de Conforto Térmico em Espaços Abertos: consideração histórica, discussão do estado da arte e proposição de classificação de modelos. Ambiente Construído, Porto Alegre, v. 7, n. 3, p. 43-58, jul./set. 2007.

NICOL, F. et al. Comfort in Outdoor Spaces in Manchester and Lewes, UK. In: WINDSOR CONFERENCE 2006: comfort and energy use in buildings: getting them right. Windsor, 2006. Proceedings... Windsor, 2006.

NIKOLOPOULOU, M.; STEEMERS, K. Thermal Comfort and Psychological Adaptation as a Guide for Designing Urban Spaces. Energy and Buildings, v. 35, n. 1, p. 95-101, jan. 2003.

OKE, T. R. Boundary Layer Climates. London: Mathuen \& Co., 1978.

OKE, T. R. Canyon Geometry and the Nocturnal Urban Heat Island: comparison of scale model and field observations. Journal of Climatology, v. 1, p. 237-254, 1981.

RIBEIRO, C. A. M.; FIDELIS, C. N.; CARVALHO, H. J. M. Fator de Visão do Céu e Ilhas de Calor: geoprocessamento aplicado ao conforto urbano. In: CONGRESSO DE PESQUISA E INOVAÇÃO DA REDE NORTE NORDESTE DE EDUCAÇÃO TECNOLÓGICA, 3., Fortaleza. 2008. Anais... Fortaleza: CONNEPI, 2008. 1 CD-ROM.

SHIMAKAWA, A. H.; BUENO-

BARTHOLOMEI, C. L. Aplicação dos Modelos Preditivos de Conforto PET e PMV em Presidente Prudente, SP: estudo de caso - parque do povo. In: ENCONTRO NACIONAL DE CONFORTO NO AMBIENTE CONSTRUÍDO, 10., 2009, Natal, RN. Anais... Natal, RN: ENTAC, 2009. 1 CDROM. 
SOUZA, L. C. L. ; RODRIGUES, D. S. ; MENDES, J. F. G. Expandindo um SIG-D para Aplicação em Conforto Ambiental em Nível Urbano. In: ENCONTRO NACIONAL SOBRE CONFORTO NO AMBIENTE CONSTRUÍDO, 7., 2003. Curitiba. Anais... Curitiba: ANTAC, 2003. p. 669-676.

SOUZA, L. C. L. Thermal Environment as a Parameter for Urban Planning. Energy

Sustainable Development, v. 11, n. 4, p. 44-53, 2007.

SPAGNOLO, J.; DE DEAR, R. A Field Study of Thermal Comfort in Outdoor and Semi-Outdoor Environments in Subtropical Sydney, Australia, Building and Environment, v. 38, p. 721-738, 2003.

SVENSSON, M. K. Sky View Factor Analysis: implications for urban air temperature differences. Meteorololy Applied, v. 11, p. 201-211, 2004.
THORSSON, S. et al. Different Methods for Estimating the Mean Radiant Temperature in an Outdoor Urban Setting. International Journal of Climatology, v. 27, n. 14, p. 1983-1993, 2007.

UNGER, J. Intra-Urban Relationship Between Surface Geometry and Urban Heat Island: review and new approach. Climate Research, v. 27, n. 3, p. 253-264, 2004.

UPMANIS, H.; CHEN, D. Influence of Geographical Factors and Meteorological Variables on Nocturnal Urban: park temperature differences, a case study of summer 1995 in Göteborg, Sweden. Climate Research, v. 13, p. 125-139, 1999.

YAMASHITA, S. et al. On Relationships Between Heat Island and Sky View Factor in the Cities of Tama River Basin, Japan. Atmospheric Environment, v. 20, p. 681-686, 1986.

Revista Ambiente Construído

Associação Nacional de Tecnologia do Ambiente Construído

Av. Osvaldo Aranha, $99-3^{\circ}$ andar, Centro

Porto Alegre - RS - Brasil CEP $90035-190$

Telefone: +55 (51) 3308-4084

Fax: +55 (51) 3308-4054

www.seer.ufrgs.br/ambienteconstruido

E-mail: ambienteconstruido@ufrgs.br 